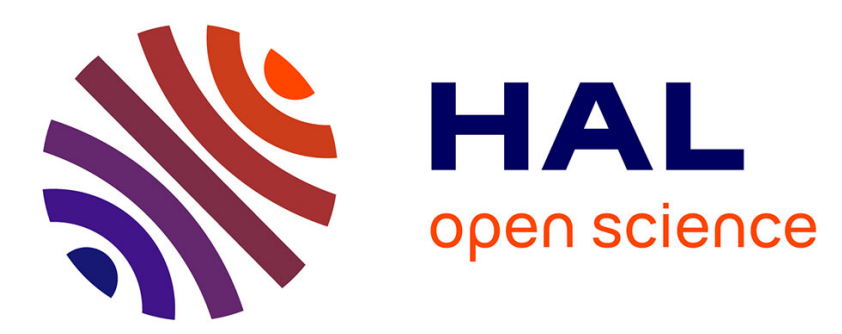

\title{
On the performance of VSI Shewhart control chart for monitoring the coefficient of variation in the presence of measurement errors
}

Huu Du Nguyen, Quoc Thong Nguyen, Kim Phuc Tran, Dang Phuc Ho

\section{- To cite this version:}

Huu Du Nguyen, Quoc Thong Nguyen, Kim Phuc Tran, Dang Phuc Ho. On the performance of VSI Shewhart control chart for monitoring the coefficient of variation in the presence of measurement errors. International Journal of Advanced Manufacturing Technology, 2019, 10.1007/s00170-01903352-7 . hal-02005536

\author{
HAL Id: hal-02005536 \\ https://hal.science/hal-02005536
}

Submitted on 14 Nov 2019

HAL is a multi-disciplinary open access archive for the deposit and dissemination of scientific research documents, whether they are published or not. The documents may come from teaching and research institutions in France or abroad, or from public or private research centers.
L'archive ouverte pluridisciplinaire HAL, est destinée au dépôt et à la diffusion de documents scientifiques de niveau recherche, publiés ou non, émanant des établissements d'enseignement et de recherche français ou étrangers, des laboratoires publics ou privés. 


\title{
On the Performance of VSI Shewhart control chart for monitoring the Coefficient of Variation in the Presence of Measurement Errors
}

\author{
Huu Du Nguyen • Quoc Thong Nguyen • \\ Kim Phuc Tran • Dang Phuc Ho
}

Received: date / Accepted: date

\begin{abstract}
In this paper, we propose a variable sampling interval Shewhart control chart to monitor the coefficient of variation (CV) squared, denoted by VSI SH- $\gamma^{2}$. The new model overcomes the ARL-biased (average run length) property of the control chart monitoring the CV in a previous study by designing two one-sided charts rather than one two-sided chart. Moreover, the effect of measurement error on the performance of the VSI SH- $\gamma^{2}$ control chart is investigated. The incorrect formula for the distribution of the $\mathrm{CV}$ in the presence of measurement error in a former study is fixed. Numerical simulations show that the precision errors and accuracy errors do have negative influences on the VSI SH- $\gamma^{2}$ chart. An appropriate strategy based on the obtained results is suggested to reduce these negative effects.
\end{abstract}

Keywords VSI control chart · Coefficient of Variation · Measurement Errors

\author{
H. D. Nguyen \\ Division of Artificial Intelligence, Dong A University, Danang, Vietnam \\ E-mail: dunh@donga.edu.vn \\ Q. T. Nguyen \\ Université de Bretagne Sud, Laboratoire de Mathématiques de Bretagne Atlantique, UMR \\ CNRS 6205, Campus de Tohannic, Vannes, France \\ E-mail: quoc-thong.nguyen@univ-ubs.fr \\ K. P. Tran \\ Ecole Nationale Supérieure des Arts et Industries Textiles, GEMTEX Laboratory, 59056 \\ Roubaix, France \\ E-mail: kim-phuc.tran@ensait.fr \\ P. Ho Dang \\ Department of Probability and Mathematical Statistics, Institute of Mathematics, Hanoi, \\ Vietnam \\ E-mail: hdphuc@math.ac.vn
}




\section{Introduction}

Coefficient of variation (CV) is an important measure of dispersion of a probability distribution. It is widely used in a large number of domains such as analytical chemistry (e.g. expressing the precision and repeatability of an assay), engineering or physics (e.g. doing quality assurance studies) and economics (e.g. determining the volatility of a security). Monitoring this characteristic of a variable has attracted the attention of many researchers. The first Shewhart control chart monitoring the CV was proposed in [11]. In [10], Hong et al. designed an exponential weighted moving average (EWMA) to monitor the CV using the intensive simulations for calculating the ARL. The EWMA was also used to monitor the CV squared in [7], where the ARL was computed by a Markov chain method. A synthetic CV control chart was next introduced in [2] while a Shewhart type chart with supplementary Run Rules to track the CV was developed in [3]. Castagliola [6] proposed a one-sided Shewhart CV chart for short production runs. In [29], the authors studied a side-sensitive group runs (SSGR) chart. The CUSUM CV chart designed in [25] outperforms the others in detecting the process shifts. Recently, the variable parameters $\mathrm{CV}$ chart has been suggested in [28]. In addition to developing new types of control chart, adaptive strategies enhancing the performance of the control chart were also developed. Some authors have explored the variable sampling interval (VSI) and variable sample size (VSS) control charts, see $[4,5,17,26]$; while [12] suggested combining VSI type with VSS type to create the VSSI $\mathrm{CV}$ control chart. An overview of control charts monitoring the CV has been discussed in [27].

For the sake of simplicity, most of aforementioned studies omitted the influence of measurement error on the control charts. However, no matter how improved the measurement method is, the measurement error is inevitable. This fact is a motivation for a large number of authors to study the consequence of measurement error on the performance of various control charts $[1$, $9,14,16,18,21,24,22]$. Among control charts monitoring the CV, the measurement error has been firstly considered by [27]. However, the authors used an assumption that the ratio $\gamma_{1}^{*} / \gamma_{0}^{*}$ (explained in Section 5) are independent from the presence of measurement error. This assumption seems to be unrealistic since the measurement errors might change the relation between the in-control and out-of-control value of the CV. Very recently, Tran et al. [23] have relaxed this assumption by letting $\gamma_{1}^{*} / \gamma_{0}^{*}$ to vary with measurement error. In this paper, we use the same measurement error model as in [23] to study the effect of measurement error on the variable sampling interval (VSI) Shewhart control chart monitoring the CV squared (denoted by VSI SH- $\gamma^{2}$ chart).

In literature, a two-sided VSI SH- $\gamma$ control chart has been already designed in [4]. However, since the distribution of the CV is skewed, the two-sided VSI SH- $\gamma$ chart is $A R L$-biased, i.e., some out-of-control average run length values are larger than the in-control value $A R L_{0}$. That was the reason why in [4], the authors have willingly omitted the decreasing shift case. We avoid this situation by designing two one-sided VSI SH- $\gamma^{2}$ control charts instead of one 
two-sided chart. A number of considerable contributions from this study can be mentioned, involving (1) we overcome the ARL-biased property of the twosided VSI SH- $\gamma$ chart, (2) we investigate the effect of measurement error on the performance of the proposed charts, and (3) we suggest a method to lower the negative effect of measurement error based on the obtained results.

The paper is organized as follows. Section 2 presents the design and the implementation of two one-sided VSI SH- $\gamma^{2}$ control charts. The performance of these two VSI SH- $\gamma^{2}$ charts is shown in Section 3 along with a direct comparison with the performance of the two-sided VSI SH- $\gamma$ chart. Section 4 is devoted to the linear covariate error model for the CV. The design and the performance of VSI SH- $\gamma^{2}$ control charts in the presence of measurement errors are presented in Section 5. Section 6 illustrates two examples of using VSI $\mathrm{SH}-\gamma^{2}$ control chart. Some concluding remarks are given in Section 7.

\section{Implementation of the one-sided VSI SH- $\gamma^{2}$ control charts}

As mentioned before, the two-sided VSI SH- $\gamma$ control chart investigated in [4] is inefficient in detecting decreasing CV shifts. We overcome this drawback of the two-sided VSI SH- $\gamma$ control chart by designing two one-sided VSI SH- $\gamma^{2}$ control charts. That is to say, we propose separately an upward control chart for detecting increasing shifts and a downward chart for detecting decreasing shifts.

Suppose that at the $i^{\text {th }}$ step of sampling, a subset of independent samples $\left\{X_{i, 1}, \ldots, X_{i, n}\right\}$ is taken, where $X_{i, j}$ follows a normal distribution with parameters $\left(\mu_{i}, \sigma_{i}\right)$. In addition, assume that the values of $\mu_{i}$ and $\sigma_{i}$ are able to change from sample to sample, but the $\mathrm{CV}$ remains stable and be equal to a predefined in-control value, i.e, $\gamma_{i}=\frac{\mu_{i}}{\sigma_{i}}=\gamma_{0} \forall i$. From this subset of samples, the sample statistic $\hat{\gamma}_{i}^{2}$ is defined as $\hat{\gamma}_{i}^{2}=\left(\frac{S_{i}}{\bar{X}_{i}}\right)^{2}$, where $\bar{X}_{i}$ and $S_{i}$ are the mean and the standard deviation of the samples $\left\{X_{i, 1}, \ldots, X_{i, n}\right\}$. The value of $\hat{\gamma}_{i}^{2}$ is then plotted in the VSI SH- $\gamma^{2}$ control charts to monitor the process. The chart parameters include the warning limit and the control limit, i.e., $\left(U C L^{+}, U W L^{+}\right)$for upward chart and $\left(L C L^{-}, L W L^{-}\right)$for downward chart.

It is customary that the control interval in the VSI chart is divided into three regions; see Figure 1 as an example for the case of upward chart. If the monitored statistic $\hat{\gamma}_{i}{ }^{2}$ drops into central region, i.e. $0<\hat{\gamma}_{i}{ }^{2}<U W L^{+}$(upward chart) or $L W L^{-}<\hat{\gamma}_{i}^{2}$ (downward chart), the process is definitely believed to be in-control, then the next sample can be taken after a longer time, say $h_{L}$. If $\hat{\gamma}_{i}^{2}$ drops into the warning region, i.e. $\hat{\gamma}_{i}^{2} \in\left[U W L^{+}, U C L^{+}\right]$(upward chart) or $\hat{\gamma}_{i}^{2} \in\left[L C L^{-}, L W L^{-}\right]$(downward chart), the process is still considered to be in-control but it seems to be gradually shifted towards out-of-control condition. The next sample should be taken after a shorter time, say $h_{S}$, to quickly detect assignable causes if they do exist. Finally, the process is considered to be outof-control if ${\hat{\gamma_{i}}}^{2}$ falls in out-of-control region, i.e., ${\hat{\gamma_{i}}}^{2}>U C L^{+}$(upward chart) or $\hat{\gamma}_{i}^{2}<L C L^{-}$(downward chart). 


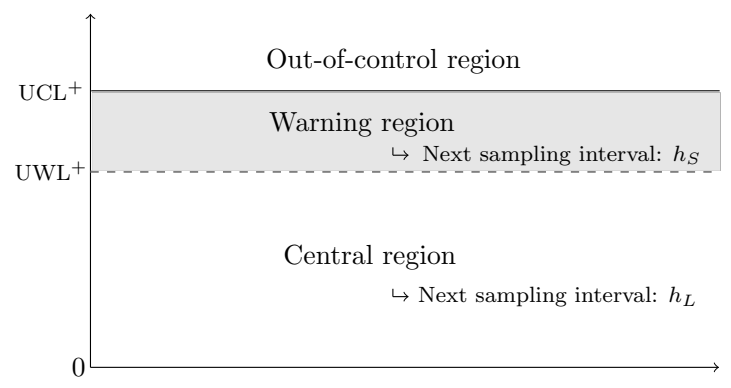

Fig. 1: Three regions and principle of the upward VSI SH- $\gamma^{2}$ control chart.

Because of the variance of sampling interval, the efficiency of the VSI type chart is usually evaluated by the average time to signal ATS. Once the control chart parameters are defined, the ATS is numerically calculated for a particular shift from an in-control value $\gamma_{0}$ to an out-of-control value $\gamma_{1}=\tau \gamma_{0}$, where $\tau$ is the shift size. The average sampling interval (ASI) is also considered to make a fair comparison with other control charts. The formulae and calculation of ATS and ASI are given in Appendix A. With the constraint on the in-control value of ATS and ASI (denoted by $A T S_{0}$ and $A S I_{0}$ ), the chart parameters $\left(U C L^{+}, U W L^{+}\right)$or $\left(L C L^{-}, L W L^{-}\right)$of the properly designed VSI $\mathrm{SH}-\gamma^{2}$ charts should be a solution of the following equations:

- for downward chart,

$$
\left\{\begin{array}{l}
A T S\left(n, h_{S}, h_{L}, L C L^{-}, L W L^{-}, \gamma_{0}, \tau=1\right)=A T S_{0} \\
A S I\left(n, h_{S}, h_{L}, L C L^{-}, L W L^{-}, \gamma_{0}, \tau=1\right)=A S I_{0}
\end{array} ;\right.
$$

- for upward chart,

$$
\left\{\begin{array}{l}
A T S\left(n, h_{S}, h_{L}, U C L^{+}, U W L^{+}, \gamma_{0}, \tau=1\right)=A T S_{0} \\
A S I\left(n, h_{S}, h_{L}, U C L^{+}, U W L^{+}, \gamma_{0}, \tau=1\right)=A S I_{0}
\end{array} .\right.
$$

\section{Performance of the one-sided VSI SH- $\gamma^{2}$ control charts without the presence of measurement errors}

According to the discussion in [20], most of the improvement in detection power of VSI type chart compared to fixed sampling interval (FSI) type chart can be obtained by using only two sampling intervals. Using only two sampling intervals also reduces the complexity of VSI scheme. We therefore assume that the sampling interval in VSI Shewhart chart is only pick from a set of two values. For the sake of comparison with the two-sided chart designed in [4], $A S I_{0}$ is set to $1, A T S_{0}$ is set to 370.4 and the following combinations of two sampling intervals $\left(h_{S}, h_{L}\right)$ are applied: $(0.5,1.5),(0.3,1.7),(0.1,1.1),(0.1,1.3)$, 
$(0.1,1.5),(0.1,1.9)$ and $(0.1,4.0)$. The experiment is implemented under the assumption that the shift size $\tau$ is deterministic, i. e. $\tau \in\{0.5,0.8,0.9,0.95\}$ for downward chart and $\tau \in\{1.05,1.1,1.2,1.5\}$ for upward chart. Table 3 provides values of $A T S_{1}$ for both FSI SH- $\gamma^{2}$ control charts (i.e. $h_{S}=h_{L}=1$ in the column titled FSI) and VSI SH- $\gamma^{2}$ control charts. Some advantages of the one-sided VSI SH- $\gamma^{2}$ control charts can be drawn from the numerical result as follows.

- Firstly, the VSI type chart is much better than the FSI type chart. This is shown by the higher values of $A T S_{1}$ in column titled FSI compared to the $A T S_{1}$ values in the same rows.

- Secondly, the decreasing process shifts, which were omitted in [4]), are detected efficiently by using the downward VSI SH- $\gamma^{2}$ chart. For example, with $n=5,\left(h_{S}, h_{L}\right)=(0.5,1.5)$ and $\gamma_{0}=0.1$, we have $A T S_{1}=13.80$ when $\tau=0.5$.

- Finally, the upward VSI SH- $\gamma^{2}$ chart perform better than the two-sided VSI SH- $\gamma$ chart in detecting the increasing process shifts. Indeed, the $A T S_{1}$ values of the upward VSI SH- $\hat{\gamma}^{2}$ chart are smaller than the ones reported in [4] for whatever the values of $n, \gamma_{0}$ and $\tau$. For instance, if $\gamma_{0}=0.05, n=$ $5, \tau=1.5$ and $\left(h_{S}, h_{L}\right)=(0.3,1.7)$, the value of $A T S_{1}$ using upward VSI $\mathrm{SH}-\gamma^{2}$ chart is 4.6 while the corresponding value using two-sided VSI SH- $\gamma$ chart is $A T S_{1}=6.0$.

Thus, our one-sided proposed charts not only overcome the ARL-biased property but also outperform the two-sided $\mathrm{SH}-\gamma$ control chart in detecting process shifts. It should be consider that in literature, there are other advanced control charts monitoring the $\mathrm{CV}$ with higher performance compared to VSI type chart. However, one should consider that the parameters in these advanced charts need to be optimized. Therefore, the Shewhart charts and its strategies versions are well-know to be easier to implement in practice. In the next sections, we will investigate the effect of measurement error on the VSI SH- $\gamma^{2}$ control charts.

\section{PLEASE INSERT TABLE 3 HERE}

\section{Linear covariate error model for the coefficient of variation}

In this Section, we briefly provide the linear covariate error model for the sample CV, which has been recently discussed in [23]. Suppose that a set of independent samples $\left\{X_{i, 1}, X_{i, 2}, \ldots, X_{i, n}\right\}$ is selected at times $i, i=1,2, \ldots$ and $X_{i, j}$ follows a normal distribution with mean $\mu_{0}+a \sigma_{0}$ and standard deviation $b \sigma_{0}$. The constants $a$ and $b$ are introduced to describe the process shift. The values $a=0$ and $b=1$ are corresponding to the in-control condition while the values $a \neq 0$ or $b \neq 1$ are corresponding to the out-of-control condition. Due to problem of measurement error, the true value of $X_{i, j}$ is not observable. Instead, we can only assessed this true value via $m$ observations 
$\left\{X_{i, j, 1}^{*}, X_{i, j, 2}^{*}, \ldots, X_{i, j, m}^{*}\right\}, m \geqslant 1$. As suggested in [13], we use the following linearly covariate error model:

$$
X_{i, j, k}^{*}=A+B X_{i, j}+\varepsilon_{i, j, k},
$$

where $X_{i, j, k}^{*}$ is the actually observed value in $k^{t h}$ measurement of the item $j$ at the $i$ sampling; $A$ and $B$ are constant parameters of the model; $\varepsilon_{i, j, k}$ is a normal $\left(0, \sigma_{M}\right)$ random error independent of $X_{i, j}$ which represents the measurement inaccuracy.

In general, mean of multiple measurements represents the true value of the interest. Let $\bar{X}_{i, j}^{*}$ be the mean of $m$ observed quantities of the same item $j$ at the $\mathrm{i}^{\text {th }}$ sampling, then

$$
\bar{X}_{i, j}^{*}=\frac{1}{m} \sum_{k=1}^{m} X_{i, j, k}^{*}=A+B X_{i, j}+\frac{1}{m} \sum_{k=1}^{m} \varepsilon_{i, j, k} .
$$

Thus, $\bar{X}_{i, j}^{*}$ also follows the normal distribution with parameters $\left(\mu^{*}, \sigma^{* 2}\right)$ in which

$$
\left\{\begin{array}{l}
\mu^{*}=A+B\left(\mu_{0}+a \sigma_{0}\right) \\
\sigma^{* 2}=B^{2} b^{2} \sigma_{0}^{2}+\frac{\sigma_{M}^{2}}{m}
\end{array} .\right.
$$

Hence, the coefficient of variation of the measured quantity $\bar{X}_{i, j}^{*}$ is

$$
\gamma^{*}=\frac{\sqrt{B^{2} b^{2} \sigma_{0}^{2}+\frac{\sigma_{M}^{2}}{m}}}{A+B\left(\mu_{0}+a \sigma_{0}\right)}=\frac{\sqrt{B^{2} b^{2}+\frac{\eta^{2}}{m}}}{\theta+B\left(1+a \gamma_{0}\right)} \times \gamma_{0},
$$

where $\eta=\frac{\sigma_{M}}{\sigma_{0}}, \gamma_{0}=\frac{\sigma_{0}}{\mu_{0}}, \theta=\frac{A}{\mu_{0}}$. By these notations, $\gamma_{0}$ is the in-control value of $\mathrm{CV}, \eta$ is the precision error ratio and $\theta$ stands for the accuracy error. It is important to consider that the measurement error also alters the relation $\gamma_{1}=\tau \gamma_{0}$ between in-control and out-of-control value of the $\mathrm{CV}$ ( $\tau$ represents the true shift size). Indeed, without measurement error, the out-of-control value $\gamma_{1}$ of the $\mathrm{CV}$ is

$$
\gamma_{1}=\frac{b \sigma_{0}}{\mu_{0}+a \sigma_{0}}=\frac{b}{1+a \gamma_{0}} \gamma_{0} .
$$

Therefore, it is easy to see that $1+a \gamma_{0}=b / \tau$. Based on this equation and (3), the in-control value of the $\mathrm{CV}$ (corresponding to $a=0$ and $b=1$ ) is

$$
\gamma_{0}^{*}=\frac{\sqrt{B^{2}+\frac{\eta^{2}}{m}}}{\theta+B} \times \gamma_{0},
$$

while the out-of-control value of the $\mathrm{CV}$ is

$$
\gamma_{1}^{*}=\frac{\sqrt{B^{2} b^{2}+\frac{\eta^{2}}{m}}}{\theta+B b / \tau} \times \gamma_{0} .
$$


Equations (4)-(5) show that in general $\gamma_{1}^{*} \neq \tau \gamma_{0}^{*}$. That is to say, the relation $\gamma_{1}^{*}=\tau \gamma_{0}^{*}$ using in [27] (Eqs. (8) and (9)) is no longer held in general situations (it only holds for the case $\theta=0$ and $b=1$ ). .

Let $\overline{\bar{X}}_{i}^{*}$ and $S_{i}^{*}$ denote the sample mean and the sample standard deviation of $\bar{X}_{1, j}^{*}, \ldots, \bar{X}_{n, j}^{*}$, i.e.,

$$
\overline{\bar{X}}_{i}^{*}=\frac{1}{n} \sum_{j=1}^{n} \bar{X}_{i, j}^{*} \text { and } S_{i}^{*}=\sqrt{\frac{1}{n-1} \sum_{j=1}^{n}\left(\bar{X}_{i, j}^{*}-\overline{\bar{X}}_{i}^{*}\right)^{2}} .
$$

Then, the sample coefficient of variation $\hat{\gamma}_{i}^{*}$ is defined by

$$
\hat{\gamma}_{i}^{*}=\frac{S_{i}^{*}}{\overline{\bar{X}}_{i}^{*}}
$$

In order to monitor the CV squared, its distribution is needed. In this paper, we apply an approximation for the cumulative distribution function (c.d.f) and the inverse distribution function (i.d.f) of the CV squared suggested in [7]; that is

$$
F_{\hat{\gamma}^{2}}(x \mid n, \gamma)=1-F_{F}\left(\frac{n}{x} \mid 1, n-1, \frac{n}{\gamma^{2}}\right)
$$

and

$$
F_{\hat{\gamma}^{2}}^{-1}(p \mid n, \gamma)=\frac{n}{F_{F}^{-1}\left(1-p \mid 1, n-1, \frac{n}{\gamma^{2}}\right)},
$$

where $F_{F}($.$) and F_{F}^{-1}($.$) is the c.d.f and i.d.f of the non-central F$ distribution.

Changing the role of $X_{i}$ in [7] by $\bar{X}_{i}^{*}$ results in the following approximation of the c.d.f and i.d.f of $\hat{\gamma}^{* 2}$ as:

$$
F_{\hat{\gamma}^{* 2}}\left(x \mid n, \gamma^{*}\right)=1-F_{F}\left(\frac{n}{x} \mid 1, n-1, \frac{n}{\gamma^{* 2}}\right),
$$

and

$$
F_{\hat{\gamma}^{* 2}}^{-1}\left(p \mid n, \gamma^{*}\right)=\frac{n}{F_{F}^{-1}\left(1-p \mid 1, n-1, \frac{n}{\gamma^{* 2}}\right)},
$$

with $\gamma^{* 2}$ is defined in $(3)$.

\section{The effect of measurement error on the VSI SH- $\gamma^{2}$ control charts}

The implementation of VSI SH- $\gamma^{2}$ control charts under the presence of measurement error is similar to the implementation of VSI SH- $\gamma^{2}$ without taking into account measurement error in Section 2. The control limit and warning limit parameters, $\left(U C L^{+}, U W L^{+}\right)$or $\left(L C L^{-}, L W L^{-}\right)$, are the solution of equations corresponding to two constrains on the in-control value of $A T S_{0}$ and $A S I_{0}$ as in (1)-(2). The difference is that the ATS and the ASI should be calculated by using the distribution of $\gamma^{* 2}$ rather than the distribution of $\gamma^{2}$ as pointed out in Appendix A. 
Similar to Section 3, the in-control values of $A T S_{0}$ and $A S I_{0}$ are set to 370.4 and 1 , respectively. The following values of parameters are applied:

- the sample sizes $n \in\{5,15\}$,

- the shift sizes $\tau \in\{0.5,0.8,0.9,0.95,1.05,1.1,1.2,1.5\}$,

- the coefficient of variation values $\gamma_{0} \in\{0.05,0.1,0.2\}$,

- the combinations of sampling interval $\left(h_{S}, h_{L}\right)=\{(0.5,1.5),(0.3,1.7)$, $(0.1,1.3),(0.1,1.5),(0.1,1.9),(0.1,4.0)\}$.

We also consider other values for parameters representing the measurement error, which are $\eta \in\{0.0,0.28,0.5,1.0\}, \theta \in\{0.0,0.03,0.05\}, B \in\{2,3,5\}$ and $m \in\{1,5,10\}$. These parameters are taken into account for a desire of covering a large range of possible scenarios of parameters. For example, $n=5$ is corresponding to moderate sample size while $n=15$ is for large sample size; $\tau=0.5$ or $\tau=1.5$ represent the large shift sizes, while $\tau=0.95$ or $\tau=1.05$ represent small shift sizes. The specific value of $\eta=0.28$ is motivated by assuming an acceptable value for the signal-to-noise ratio (see AIAG guidelines [15]), while the value of $\eta=1.0$ is to describe a large accuracy error. The values of $\left(h_{S}, h_{L}\right)$ follows those suggested in [19]. In our study, the numerical results have also been obtained for a number of other combinations of parameters, but they are not presented here and are available upon request from authors.

Without loss of generality, we suppose that $b=1$. Tables 4-7 present the control limit and warning limit for both upward and downward charts. It is considered from these tables that the control limit does not depend on the sampling interval and the shift size. This result can be proven as follows. Since $A S I_{0}=1$, equation (16) leads to $h_{S} p_{S 0}+h_{L} p_{L 0}=1-q_{0}$, in which $p_{S 0}, p_{L 0}$ and $q_{0}$ are the corresponding in-control values of the probabilities $p_{S}, p_{L}$ and $q$. Substituting this result into (17), we obtain

- for upward chart,

$$
\frac{1}{A T S_{0}}=q_{0}=1-F_{\gamma^{* 2}}\left(U C L^{+} \mid n, \gamma_{0}^{*}\right),
$$

- for downward chart,

$$
\frac{1}{A T S_{0}}=q_{0}=F_{\gamma^{* 2}}\left(L C L^{-} \mid n, \gamma_{0}^{*}\right) .
$$

That means $U C L^{+}$and $L C L^{-}$do not depend on $\left(h_{S}, h_{L}\right)$ and $\tau$.

PLEASE INSERT TABLE 4 HERE
PLEASE INSERT TABLE 5 HERE
PLEASE INSERT TABLE 6 HERE
PLEASE INSERT TABLE 7 HERE

Tables 8-12 present the corresponding values of $A T S_{1}$ based on the values of control limit and warning limit in the Tables 4-7. The $A T S_{1}$ value of the Shewhart- $\gamma^{2}$ control chart under the presence of measurement error based on corrected formula is calculated again and presented in the second column 
of the Tables 8-12 (FSI columns). As expected, the VSI feature in general enhance remarkably the efficiency of Shewhart- $\gamma^{2}$ regardless the presence of measurement error. The values of $A T S_{1}$ using FSI SH- $\gamma^{2}$ control chart are always larger than those the values of $A T S_{1}$ using VSI SH- $\gamma^{2}$ control chart with the same parameters. For example, with $n=5, \tau=0.8, \eta=0.28, \theta=$ $0.05, B=1, m=1$ and $\gamma_{0}=0.05$ in Table 8 , we have $A T S_{1}=162.03$ in FSI chart, larger than any value of $A T S_{1}$ in the same row.

The results in Tables 8-10 show that both the precision and accuracy errors have negative influence on the chart performance but with different level. While the increase of $\theta$ leads to the significant increase of $A T S_{1}$ (Table 10), the increase of $A T S_{1}$ is insignificant as $\eta$ increases (Table 8). For example, with $n=5, B=1, m=1, \gamma_{0}=0.1, \theta=0.05, \tau=1.1$ and $\left(h_{S}, h_{L}\right)=(0.1,1.5)$, we have $A T S_{1}=98.84$ when $\eta=0.2$ and $A T S_{1}=99.54$ when $\eta=1$ (Table 8). With the same value of $n, B, m, \gamma_{0}, \tau,\left(h_{S}, h_{L}\right)$ and $\eta=0.28$, we have $A T S_{1}=92.88$ when $\theta=0$ and $A T S_{1}=98.86$ when $\theta=0.05$ (Table 10).

\section{PLEASE INSERT TABLE 8 HERE \\ PLEASE INSERT TABLE 9 HERE \\ PLEASE INSERT TABLE 10 HERE}

In contrast to $\theta$ and $\eta$, the larger the value of constant coefficient $B$ in linear covariate error model, the smaller the value of $A T S_{1}$. That is to say, the increase of $B$ enhances slightly the chart performance. For instance, we obtain $A T S_{1}=5.19$ when $B=2$ and $A T S_{1}=5.13$ when $B=5$ with the same $n=5, \eta=0.028, \theta=0.01, m=1, \tau=1.5,\left(h_{S}, h_{L}\right)=(0.5,1.5)$ in Table 11.

\section{PLEASE INSERT TABLE 11 HERE}

To deal with the problem of measurement error, a common approach is to use multiple measures for the same item. However, the obtained result in Table 12 show that this method is inefficient in enhancing the efficiency of VSI SH- $\gamma^{2}$ control chart. As the value of $m$ increases from 1 to 10 , the $A T S_{1}$ remains unchanged or reduces negligibly. For instance, with $n=5, \tau=0.8,\left(h_{S}, h_{L}\right)=$ $(0.1,1.1), \eta=0.28, \theta=0.05, B=1, \gamma_{0}=0.05$, we have $A T S_{1}=146.50$ when $m=1$ and $A T S_{1}=146.49$ when $m=10$.

\section{PLEASE INSERT TABLE 12 HERE}

In many practical situations, it is difficult for practitioners to determine a specific shift size. Considering the shift size as a random variable and selecting a probability distribution is suggested to model it. Several potential statistical distributions is provided in [8]. In the case the quality practitioners do not have any reference for the shift size, the uniform distribution can be used which gives an equal weight to each shift size included within the interval $\Omega=[a, b]$. The performance of VSI SH- $\gamma^{2}$ now is measured by expected average time to sign,

$$
E A T S=\int_{a}^{b} A T S \times f(\tau) d \tau,
$$

where $f(\tau)=\frac{1}{b-a}$ over the range $[a, b]$. The chart parameters is now the solution of following equations: 
- for downward chart,

$$
\left\{\begin{array}{l}
\operatorname{EATS}\left(n, h_{S}, h_{L}, L C L^{-}, L W L^{-}, \gamma_{0}, \tau=1\right)=A T S_{0} \\
A S I\left(n, h_{S}, h_{L}, L C L^{-}, L W L^{-}, \gamma_{0}, \tau=1\right)=A S I_{0}
\end{array}\right.
$$

- for upward chart,

$$
\left\{\begin{array}{l}
E A T S\left(n, h_{S}, h_{L}, U C L^{+}, U W L^{+}, \gamma_{0}, \tau=1\right)=A T S_{0} \\
A S I\left(n, h_{S}, h_{L}, U C L^{+}, U W L^{+}, \gamma_{0}, \tau=1\right)=A S I_{0} .
\end{array}\right.
$$

The value of EATS is computed based on these chart parameters. We consider two situations, $[a, b]=[0.5,1)$ corresponding to the decreasing case, denoted by (D) and $[a, b]=(1,1.5]$ corresponding to the increasing case, denoted by (I). Tables 13-16 show the impact of parameters $\eta, \theta, B$ and $m$ on the overall performance of VSI SH- $\gamma^{2}$ control charts. In general, it can be seen that the EATS values in these tables show a similar tendency as for the deterministic shift size results discussed above. That is: (1) the measurement errors (represented by $\eta$ and $\theta$ ) have a negative effect on the power of the VSI SH- $\gamma^{2}$ chart, (2) the coefficient $B$ in the linear covariate model can reduce the negative effect of measurement errors, and (3) taking more measurements per item in each sample is not an efficient way to compensate for the effect of measurement errors. Moreover, some more conclusion can be drawn as follows.

- EATS values are always larger for the decreasing case compared to the increasing case. For example, with $n=15, \theta=0.05, \eta=0.2, m=1, B=$ $1, \gamma_{0}=0.05,\left(h_{S}, h_{L}\right)=(0.5,1.5)$ we have $E A T S_{1}=40.57$ for the decreasing case and $E A T S_{1}=12.65$ for the increasing case (Table 13). That means it is easier for VSI SH- $\gamma^{2}$ to detect upward shifts than the downward shifts. This can be explained by the asymmetric property of the CV distribution.

- The value of $\left(h_{S}, h_{L}\right)=(0.1,4.0)$, corresponding to the widest interval among the intervals suggested by [19], results in the smallest values of EATS. This couple is then recommended to reduce the effect of measurement errors on the chart performance.

- The control chart sensitivity is improved remarkably with the sample size. As $n$ increases from 5 to 15 , the values of EATS reduce by more than half. For example, with $\theta=0.03, \eta=0.28, m=1, B=1, \gamma_{0}=0.05$ and $\left(h_{S}, h_{L}\right)=(0.1,1.5)$, we have $E A T S_{1}=22.46$ when $n=5$ and $E A T S_{1}=$ 10.65 when $n=15$ (Increasing case in Table 14). Therefore, a larger sample size is a very effective way to enhance the chart efficiency.

PLEASE INSERT TABLE 13 HERE

PLEASE INSERT TABLE 14 HERE

PLEASE INSERT TABLE 15 HERE

PLEASE INSERT TABLE 16 HERE 


\section{Application in real industrial scenarios}

The use of control charts is widespread in many industrial processes where the assignable causes and out-of-control conditions should be detected as soon as possible to ensure the product quality and reduce waste. In practice, the data are collected by measuring samples taken during production. The interest characteristic (which is the CV squared in our study) is calculated directly from these observed data, which commonly contain measurement error. That is to say, the obtained value of the CV is under the presence of measurement error (denoted by $\gamma^{* 2}$ ). As a result, the characteristic we monitor in practice should be $\gamma^{* 2}$, but not the true value $\gamma^{2}$ (we do not observe this exact value due to measurement error). However, by monitoring $\gamma^{* 2}$ using the linear covariate error model, we can still detect the change in the true value of the CV. An important issue related to choosing the proper parameters of the model can be arisen in practice. This is equivalent to how to determine the parameters in the linear covariate regression model (using in a measurement system). A number of techniques to deal with this problem are provided in [15] (Section B).

\subsection{Example 1: Sintering process}

In this Section, we illustrate the implementation of VSI SH- $\gamma^{2}$ control chart in the presence of measurement errors. We consider a simulated set of data from a sintering process in an Italian company that manufactures sintered mechanical parts. This context is similar to the scenario presented in [7]. The process manufactures parts have to ensure a pressure test drop time $T_{p d}$ from 2 bar to 1.5 bar more than $30 \mathrm{sec}$, which is a quality characteristic related to the pore shrinkage. It is stated that the preliminary regression study relating $T_{p d}$ to the quantity $Q_{C}$ of molten copper has demonstrated the presence of a constant proportionality $\sigma_{p d}=\gamma_{p d} \times \mu_{p d}$ between the standard deviation of the pressure drop time and its mean. The quality practitioner then decided to monitor the coefficient of variation $\gamma_{p d}=\sigma_{p d} / \mu_{p d}$ to detect changes in the process variability.

From a Phase I dataset, an estimated $\hat{\gamma}_{0}=0.01$ is computed based on root mean square computation. The related parameters of the linear covariate error model are supposed to be $\eta=0.28, \theta=0, B=1$, and $m=1$. A dataset of 20 observations with sample size $n=5$ is measured for phase II. For each sample $i=1,2, \ldots, 20$, the sample mean $\bar{X}_{i}^{*}$, the sample standard deviation $S_{i}^{*}$ and the sample CV squared $\hat{\gamma}_{i}^{* 2}=\left(\frac{\bar{X}_{i}^{*}}{S_{i}^{*}}\right)^{2}$ have been computed and presented in Table 1. In this simulated data, the process is assumed to run in-control up to sample \#9. Then, between samples \#10 and \#12, we have simulated the occurrence of a cause shifting $\gamma_{p d}$ from $\gamma_{p d}=0.01$ to $\gamma_{p d}=0.011$, i.e. $\tau=1.1$.

In this example, the downward and the upward control charts are implemented with $h_{S}=0.1$ and $h_{L}=4.0$. Based on the numerical procedure in Section 5 with $A T S_{0}=370.4$, for the downward VSI SH- $\gamma^{2}$ chart, the control 


\begin{tabular}{ccccc} 
Subgroup $i$ & $\bar{X}_{i}^{*}$ & $S_{i}^{*}$ & $\hat{\gamma}_{i}^{*}$ & $\hat{\gamma}_{i}^{* 2}$ \\
\hline 1 & 595.7 & 4.729 & 0.0079 & 0.00006 \\
2 & 602.6 & 7.215 & 0.0120 & 0.00014 \\
3 & 603.7 & 7.642 & 0.0127 & 0.00016 \\
4 & 603.5 & 4.520 & 0.0075 & 0.00006 \\
5 & 597.5 & 4.856 & 0.0081 & 0.00007 \\
6 & 597.4 & 6.130 & 0.0103 & 0.00011 \\
7 & 603.0 & 3.658 & 0.0061 & 0.00004 \\
8 & 602.4 & 8.528 & 0.0142 & 0.00020 \\
9 & 592.1 & 9.307 & 0.0157 & 0.00025 \\
10 & 604.3 & 14.201 & 0.0235 & 0.00055 \\
11 & 596.4 & 13.092 & 0.0220 & 0.00048 \\
12 & 602.8 & 12.607 & 0.0209 & 0.00044 \\
13 & 602.7 & 4.420 & 0.0073 & 0.00005 \\
14 & 605.0 & 5.940 & 0.0098 & 0.00010 \\
15 & 597.0 & 4.453 & 0.0075 & 0.00006 \\
16 & 599.5 & 4.331 & 0.0072 & 0.00005 \\
17 & 601.1 & 9.291 & 0.0155 & 0.00024 \\
18 & 604.6 & 2.070 & 0.0034 & 0.00001 \\
19 & 598.6 & 6.086 & 0.0102 & 0.00010 \\
20 & 597.3 & 5.208 & 0.0087 & 0.00008 \\
\hline
\end{tabular}

Table 1: Illustrative example of Phase II dataset from a sintering process.

and warning limits with measurement error are $L C L^{-}=0.0000040623$ and $L W L^{-}=0.00015128$, respectively. The downward chart is illustrated in Figure 2. It can be seen from Table 1 and Figure 2 that most of the monitoring values are above the warning limit, and no value is below the control limit. This is reasonable since there is no decrease shift in the process.

For the upward case, the control limit and warning limit are equal to $U C L^{+}=0.00043826$ and $U W L^{+}=0.000048914$, respectively. The upward chart is illustrated in Figure 3. Most of the sample CV values are in the warning region, the samples $\# 10, \# 11$ and \#12 are detected as out-of-control. As we know, the change of the process is simulated from sample \#10, which means the chart detects the true shift at time 4.8 (time unit). In this particular example, the time required for the VSI SH- $\gamma^{2}$ chart to detect the process shift is much less than the time that would have been necessary with the Shewhart chart (10 time unit).

\subsection{Example 2: Die casting hot chamber process}

Let us consider another scenario from a die casting hot chamber process introduced in [4]. A set of data has been simulated based on a context given by a Tunisian company manufacturing zinc alloy (ZAMAK) parts for the sanitary 


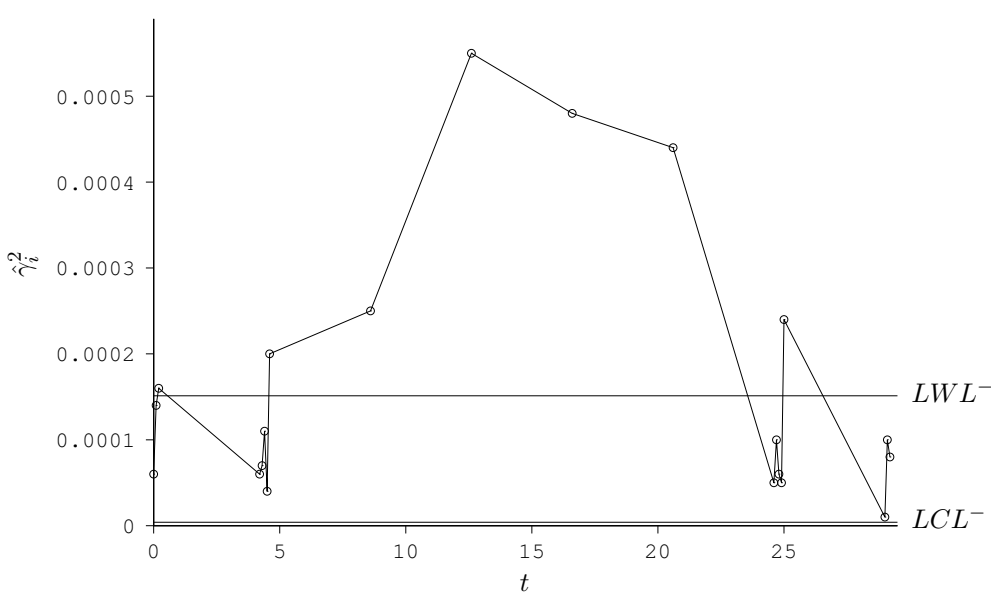

Fig. 2: The downward VSI SH- $\gamma^{2}$ control chart with $h_{S}=0.1$ and $h_{L}=4.0$ in the presence of measurement error for the industrial data-set in Table 1.

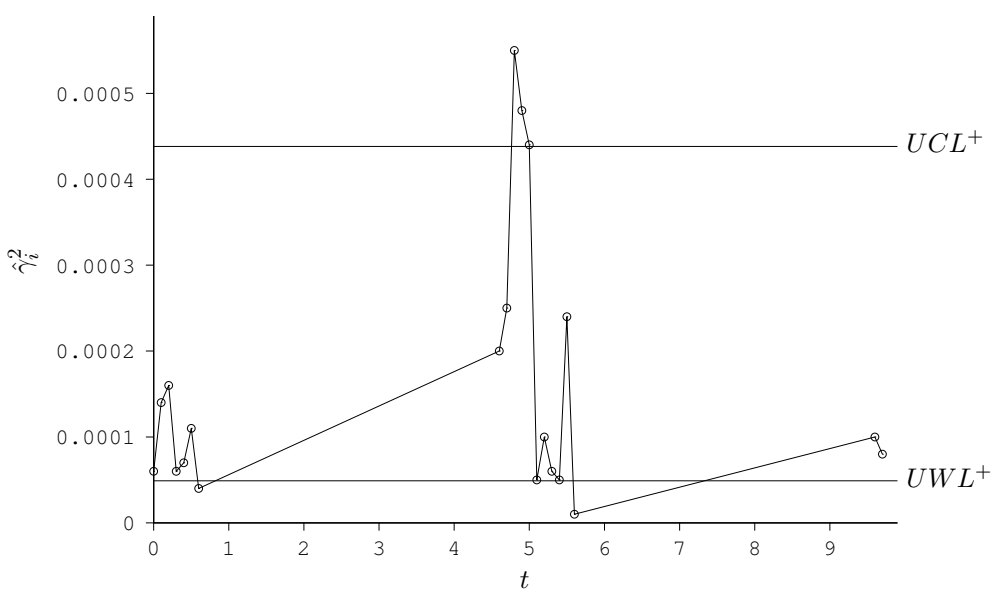

Fig. 3: The upward VSI SH- $\gamma^{2}$ control chart with $h_{S}=0.1$ and $h_{L}=4.0$ in the presence of measurement error for the industrial data-set in Table 1.

sector. The weight ( $X$, in grams) of scrap zinc alloy material to be removed between the molding process and the continuous plating surface treatment is the character of interest. The presence of a constant proportionality $\sigma=\gamma \times \mu$ between the standard deviation $\sigma$ and the mean $\mu$ of the weight of scrap alloy has been illustrated by a preliminary regression study. With the regression study, the in-control CV $\gamma_{0}$ has been estimated to 0.01 .

According to the process engineer, the most important special cause that leads to an anomalous increase in $\sigma$ is due to the shift from the nominal value 
of the injection pressure of the zinc alloy into the die. In fact, the injection pressure holds the molten metal into the die during solidification. As a result, this variation can lead to an uncontrolled item solidification leading to excessive scrap material.

\begin{tabular}{ccccc} 
Subgroup $i$ & $\bar{X}_{i}^{*}$ & $S_{i}^{*}$ & $\hat{\gamma}_{i}^{*}$ & $\hat{\gamma}_{i}^{* 2}$ \\
\hline 1 & 449.0 & 5.491 & 0.0122 & 0.00015 \\
2 & 453.0 & 4.354 & 0.0096 & 0.00009 \\
3 & 451.5 & 7.137 & 0.0158 & 0.00025 \\
4 & 455.2 & 4.888 & 0.0107 & 0.00012 \\
5 & 447.0 & 7.660 & 0.0171 & 0.00029 \\
6 & 446.3 & 2.629 & 0.0059 & 0.00003 \\
7 & 445.3 & 6.016 & 0.0135 & 0.00018 \\
8 & 451.5 & 3.324 & 0.0074 & 0.00005 \\
9 & 451.4 & 2.311 & 0.0051 & 0.00003 \\
10 & 448.3 & 5.782 & 0.0129 & 0.00017 \\
11 & 449.7 & 7.656 & 0.0170 & 0.00029 \\
12 & 447.7 & 3.406 & 0.0076 & 0.00006 \\
13 & 454.0 & 8.420 & 0.0185 & 0.00034 \\
14 & 451.0 & 4.885 & 0.0108 & 0.00012 \\
15 & 452.3 & 3.989 & 0.0088 & 0.00008 \\
16 & 450.7 & 8.315 & 0.0184 & 0.00034 \\
17 & 446.5 & 3.645 & 0.0082 & 0.00007 \\
18 & 450.2 & 9.553 & 0.0212 & 0.00045 \\
19 & 449.3 & 10.131 & 0.0225 & 0.00051 \\
20 & 449.2 & 4.186 & 0.0093 & 0.00009 \\
21 & 452.2 & 4.788 & 0.0106 & 0.00011 \\
22 & 448.7 & 3.890 & 0.0087 & 0.00008 \\
23 & 449.7 & 8.613 & 0.0192 & 0.00037 \\
24 & 450.1 & 7.376 & 0.0164 & 0.00027 \\
25 & 449.8 & 5.475 & 0.0122 & 0.00015 \\
26 & 451.9 & 4.399 & 0.0097 & 0.00009 \\
27 & 450.6 & 4.310 & 0.0096 & 0.00009 \\
28 & 453.4 & 3.627 & 0.0080 & 0.00006 \\
29 & 450.5 & 4.806 & 0.0107 & 0.00011 \\
30 & 450.9 & 4.358 & 0.0097 & 0.00009 \\
\hline & & & &
\end{tabular}

Table 2: Illustrative example of Phase II dataset from a zinc alloy die casting hot chamber process.

Similar to the first example, the data is simulated under the presence of measurement error with $\eta=0.28, \theta=0, B=1$, and $m=1$ for the parameters of the linear covariate error mode. The dataset of 30 samples of size $n=5$ is measured for phase II. For each sample $i=1,2, \ldots, 30$, the sample mean $\bar{X}_{i}^{*}$, 
the sample standard deviation $S_{i}^{*}$ of scrap alloy and the sample CV squared $\hat{\gamma}_{i}^{* 2}$ have been computed (see Table 2). In this simulated data, the process is assumed to run in-control up to sample \#17. Then, between samples \#18 and $\# 19$, we have simulated an increase of $20 \%$ of CV (i.e. $\tau=1.2$ ).

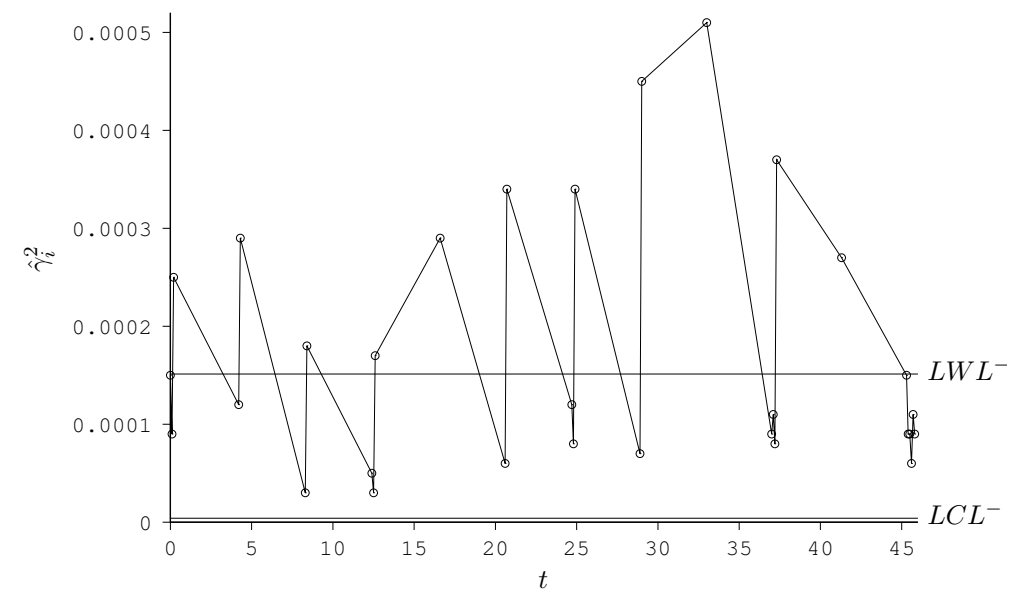

Fig. 4: The downward VSI SH- $\gamma^{2}$ control chart with $h_{S}=0.1$ and $h_{L}=4.0$ in the presence of measurement error for the industrial data-set in Table 2.

We implement the downward and the upward control charts with $h_{S}=$ $0.1, h_{L}=4.0$ and $A T S_{0}=370.4$. Therefore, the control and warning limits with measurement error are the same as the previous example, i.e. $L C L^{-}=$ $0.0000040623, L W L^{-}=0.00015128$ for the downward chart and $U C L^{+}=$ $0.00043826, U W L^{+}=0.000048914$ for the upward chart. Figure 4 shows the operation of the downward chart. As expected, there is no detection from this figure since only the upward shift is simulated.

The operation of upward VSI SH- $\gamma^{2}$ chart is illustrated in Figure 5. The control chart triggers a signal by plotting points \#18 and\#19 above the control limit $U C L^{+}=0.00043826$. This figure confirms that these two batches are out-of-control. After the corrective actions, samples collected from successive batches do not show any anomaly. The upward VSI SH- $\gamma^{2}$ chart requires only 9.5 (time unit) to detect the change in the process, while the Shewhart chart needs 18 samples (i.e. 18 time unit).

\section{Concluding remarks}

We have investigated in this paper two one-sided VSI Shewhart control charts for monitoring the coefficient of variation squared. In comparison with the two-sided chart suggested in [4], using two-sided charts leads to better performance in detecting both downward shifts and upward shifts. The effect of 


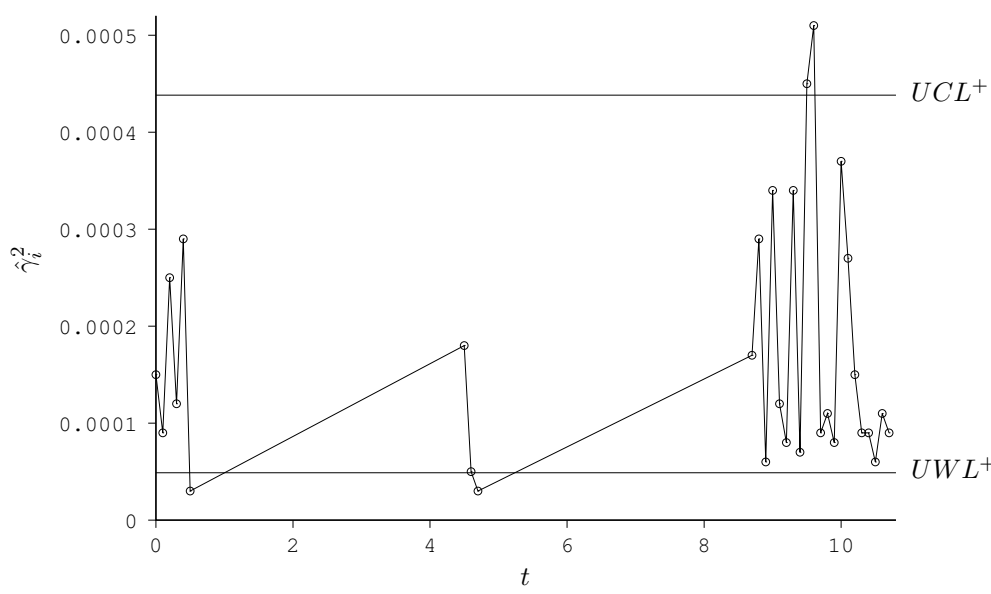

Fig. 5: The upward VSI SH- $\gamma^{2}$ control chart with $h_{S}=0.1$ and $h_{L}=4.0$ in the presence of measurement error for the industrial data-set in Table 2.

measurement error on the performance of VSI SH $-\gamma^{2}$ control chart using a linear covariate error model is also discovered. The numerical results show that the measurement error has negative influences on the proposed control charts: The larger the value of precision errors and especially accuracy errors, the larger the value of average time to signal. Studying the effect of each parameters on the chart performance suggests us some efficient strategies to reduce these negative impacts as well as enhance the efficiency of the proposed charts, involving increasing the sample size $n$ or choosing the couple of sampling interval $\left(h_{S}, h_{L}\right)$ with width as large as possible (which is $(0.1,4.0)$ in this study). It is also worthy to consider that increasing the number of multiple measurement per item is not a good strategy since it reduces insignificantly the chart efficiency in the presence of measurement error.

Acknowledgements The authors thank the anonymous referees for their insightful and valuable suggestions which helped to improve the quality of the final manuscript.

\section{References}

1. Bennet, C.: Effect of measurement error on chemical process control. Industry Quality Control 10(4), 17-20 (1954)

2. Calzada, M., Scariano, S.M.: A synthetic control chart for the coefficient of variation. Journal of Statistical Computation and Simulation 83(5), 853-867 (2013)

3. Castagliola, P., Achoure, A., Taleb, H., Celano, G., Psarakis, S.: Monitoring the coefficient of variation using control charts with run rules. Quality Technology \& Quantitative Management 10, 75-94 (2013)

4. Castagliola, P., Achouri, A., Taleb, H., Celano, G., Psarakis, S.: Monitoring the coefficient of variation using a variable sampling interval control chart. Quality and Reliability Engineering International 29(8), 1135-1149 (2013) 
5. Castagliola, P., Achouri, A., Taleb, H., Celano, G., Psarakis, S.: Monitoring the coefficient of variation using a variable sample size control chart. The International Journal of Advanced Manufacturing Technology 81(9-12), 1561-1576 (2015)

6. Castagliola, P., Amdouni, A., Taleb, H., Celano, G.: One-sided Shewhart-type charts for monitoring the coefficient of variation in short production runs. Quality Technology and Quantitative Management 12(1), 53-67 (2015)

7. Castagliola, P., Celano, G., Psarakis, S.: Monitoring the coefficient of variation using ewma charts. Journal of Quality Technology 43(3), 249-265 (2011)

8. Celano, G., Castagliola, P., Nenes, G., Fichera, S.: Performance of $t$ control charts in short runs with unknown shift sizes. Computers \& Industrial Engineering 64, 56-68 (2013)

9. Costa, A., Castagliola, P.: Effect of measurement error and autocorrelation on the $\bar{X}$ chart. Journal of Applied Statistics 38(4), 661-673 (2011)

10. Hong, E.P., Kang, C.W., Baek, J.W., Kang, H.W.: Development of cv control chart using ewma technique. Journal of the society of Korea Industrial and Systems Engineering 31 (2008)

11. Kang, C., Lee, M., Seong, Y., Hawkins, D.: A control chart for the coefficient of variation. Journal of Quality Technology 39(2), 151-158 (2007)

12. Khaw, K., Khoo, M., Yeong, W., Wu, Z.: Monitoring the coefficient of variation using a variable sample size and sampling interval control chart. Communications in Statistics - Simulation and Computation 46(7), 5722-5794 (2017)

13. Li, Z., Zou, C., Gong, Z., Wang, Z.: The computation of average run length and average time to signal: an overview. Journal of Statistical Computation and Simulation 84(8), 1779-1802 (2014)

14. Linna, K., Woodall, W.: Effect of measurement error on Shewhart control chart. Journal of Quality Technology 33(2), 213-222 (2001)

15. Manual: Measurement system analysis. Automotive Industry Action Group, fourth edn (2010)

16. Maravelakis, P.: Measurement error effect on the CUSUM control chart. Journal of Applied Statistics 39(2), 323-336 (2012)

17. Nguyen, H.D., Tran, K.P., Heuchenne, C.: Monitoring the ratio of two normal variables using variable sampling interval exponentially weighted moving average control charts. Quality and Reliability Engineering International 35(1), 439-460 (2019). DOI 10.1002 /qre.2412

18. Noorossana, R., Zerehsaz, Y.: Effect of measurement error on phase II monitoring of simple linear profiles. The International Journal of Advanced Manufacturing Technology 79(9-12), 2031-2040 (2015)

19. Reynolds, M., Amin, R., Arnold, J., Nachlas, J.: $\bar{X}$ charts with variable sampling intervals. Technometris 30(2), 181-192 (1988)

20. Reynolds, M., Arnold, J.: Optimal one-sided shewhart charts with variable sampling interval. Sequential Analysis 80(1), 181-192 (1989)

21. Tran, K., Castagliola, P., Celano, G.: The performance of the Shewhart-RZ control chart in the presence of measurement error. International Journal of Production Research 54, 7504-7522 (2016)

22. Tran, K.P., Castagliola, P., Celano, G., Khoo, M.B.: Monitoring compositional data using multivariate exponentially weighted moving average scheme. Quality and Reliability Engineering International 34(3), 391-402 (2018)

23. Tran, K.P., Heuchenne, C., Balakrishnan, N.: On the performance of coefficient of variation charts in the presence of measurement errors. Quality and Reliability Engineering International 35(1), 329-350 (2019). DOI 10.1002/qre.2402

24. Tran, P., Tran, K., Rakitzis, A.: A synthetic median control chart for monitoring the process mean with measurement errors. Quality and Reliability Engineering International (2019). DOI 10.1002/qre.2447

25. Tran, P., Tran, K.P.: The efficiency of CUSUM schemes for monitoring the coefficient of variation. Applied Stochastic Models in Business and Industry 32(6), 870-881 (2016)

26. Yeong, W.., Khoo, M., Lim, S., Lee, M.: A direct procdedure for monitoring the coefficient of variation using a variable sample size sheme. Communications in Statistics Simulation and Computation 46(6), 4210-4225 (2017) 
27. Yeong, W., Khoo, M., Lim, S., Teoh, W.: The coefficient of variation chart with measurement error. Quality Technology \& Quantitative Management pp. 1-25 (2017)

28. Yeong, W.C., Lim, S.L., Khoo, M.B.C., Castagliola, P.: Monitoring the coefficient of variation using a variable parameters chart. Quality Engineering 30(2), 212-235 (2018)

29. You, H., Khoo, B.M., Castagliola, P., Haq, A.: Monitoring the coefficient of variation using the side sensitive group runs chart. Quality and Reliability Engineering International 32(5), 1913-1927 (2016)

\section{A Appendix}

Let $p_{S}, p_{L}$ and $q$ be the probability that a monitored sample point drops into the central region, the warning region and the out-of-control region, respectively. According to the subdivision of control interval, the formulae to calculate $p_{S}, p_{L}$ and $q$ in VSI SH- $\gamma^{2}$ without considering the measurement errors are as follows.

- For downward chart,

$$
\begin{aligned}
p_{L} & =P\left(\hat{\gamma}^{2} \geq L W L^{-}\right)=1-F_{\hat{\gamma}^{2}}\left(L W L^{-} \mid n, \gamma^{2}\right), \\
p_{S} & =P\left(L C L^{-} \leqslant \hat{\gamma}^{2} \leqslant L W L^{-}\right) \\
& =F_{\hat{\gamma}^{2}}\left(L W L^{-} \mid n, \gamma^{2}\right)-F_{\hat{\gamma}^{2}}\left(L C L^{-} \mid n, \gamma^{2}\right) \\
q & =P\left(\hat{\gamma}^{2}<L C L^{-}\right)=1-p_{S}-p_{L} .
\end{aligned}
$$

- For upward chart,

$$
\begin{aligned}
p_{L} & =P\left(\hat{\gamma}^{2} \leqslant U W L^{+}\right)=F_{\hat{\gamma}^{2}}\left(U W L^{+} \mid n, \gamma^{2}\right), \\
p_{S} & =P\left(U W L^{+} \leqslant \hat{\gamma}^{2} \leqslant U C L^{+}\right) \\
& =F_{\hat{\gamma}^{2}}\left(U C L^{+} \mid n, \gamma^{2}\right)-F_{\hat{\gamma}^{2}}\left(U W L^{+} \mid n, \gamma^{2}\right), \\
q & =P\left(\hat{\gamma}^{2}>U C L^{+}\right)=1-p_{S}-p_{L} .
\end{aligned}
$$

The c.d.f $F_{\hat{\gamma}^{2}}\left(. \mid n, \gamma^{2}\right)$ in this case is defined in (6).

In the VSI SH- $\gamma^{2}$ control charts considering the presence of measurement errors, the formulae for $p_{S}, p_{L}$ and $q$ are the same in equations (10)-(15) for both charts, but the distribution $F_{\gamma^{2}}\left(. \mid n, \gamma^{2}\right)$ in these equations are replaced by $F_{\gamma^{* 2}}\left(. \mid n, \gamma^{* 2}\right)$, defined in (8).

From its definition, the ASI is calculated by

$$
A S I=E(h)=\frac{h_{S} p_{S}+h_{L} p_{L}}{1-q} .
$$

The formula of ATS is given by [20] and adopted by [4] as

$$
A T S=\frac{h_{S} p_{S}+h_{L} p_{L}}{q(1-q)} .
$$




\begin{tabular}{|c|c|c|c|c|c|c|c|c|c|}
\hline & & \multirow[t]{2}{*}{ FSI } & \multicolumn{7}{|c|}{ VSI } \\
\hline & & & $(0.5,1.5)$ & $(0.3,1.7)$ & $(0.1,1.1)$ & $(0.1,1.3)$ & $(0.1,1.5)$ & $(0.1,1.9)$ & $(0.1,4.0)$ \\
\hline$\tau$ & $\gamma_{0}$ & \multicolumn{8}{|c|}{$n=5$} \\
\hline \multirow[t]{3}{*}{0.5} & .05 & 26.91 & 13.71 & 8.43 & 12.90 & 6.12 & 4.23 & 3.16 & 2.71 \\
\hline & 0.1 & 27.07 & 13.80 & 8.49 & 13.03 & 6.19 & 4.28 & 3.19 & 2.73 \\
\hline & 0.2 & 27.72 & 14.15 & 8.73 & 13.54 & 6.48 & 4.47 & 3.30 & 2.79 \\
\hline \multirow[t]{3}{*}{0.8} & .05 & 156.19 & 119.29 & 104.53 & 140.34 & 120.23 & 106.93 & 89.77 & 56.89 \\
\hline & 0.1 & 156.67 & 119.79 & 105.03 & 140.85 & 120.75 & 107.45 & 90.28 & 57.30 \\
\hline & 0.2 & 158.56 & 121.73 & 107.00 & 142.84 & 122.80 & 109.50 & 92.27 & 58.96 \\
\hline \multirow[t]{3}{*}{0.9} & .05 & 246.01 & 218.26 & 207.16 & 236.04 & 221.75 & 211.22 & 196.06 & 159.37 \\
\hline & 0.1 & 246.42 & 218.74 & 207.66 & 236.47 & 222.22 & 211.71 & 196.59 & 159.94 \\
\hline & 0.2 & 247.99 & 220.57 & 209.61 & 238.16 & 224.05 & 213.64 & 198.64 & 162.19 \\
\hline \multirow[t]{3}{*}{0.95} & .05 & 303.41 & 286.87 & 280.25 & 297.87 & 289.57 & 283.20 & 273.64 & 248.28 \\
\hline & 0.1 & 303.67 & 287.18 & 280.59 & 298.15 & 289.87 & 283.52 & 274.00 & 248.71 \\
\hline & 0.2 & 304.66 & 288.40 & 281.90 & 299.22 & 291.06 & 284.80 & 275.39 & 250.41 \\
\hline \multirow[t]{3}{*}{1.05} & .05 & 189.91 & 180.56 & 176.82 & 183.99 & 179.04 & 176.29 & 173.08 & 167.52 \\
\hline & 0.1 & 190.48 & 181.15 & 177.41 & 184.57 & 179.63 & 176.88 & 173.68 & 168.13 \\
\hline & 0.2 & 192.85 & 183.56 & 179.85 & 186.98 & 182.07 & 179.33 & 176.14 & 170.60 \\
\hline \multirow[t]{3}{*}{1.1} & .05 & 107.13 & 97.10 & 93.09 & 100.21 & 95.00 & 92.23 & 89.08 & 83.82 \\
\hline & 0.1 & 107.73 & 97.69 & 93.68 & 100.81 & 95.59 & 92.81 & 89.66 & 84.39 \\
\hline & 0.2 & 110.21 & 100.12 & 96.09 & 103.28 & 98.03 & 95.24 & 92.06 & 86.73 \\
\hline \multirow[t]{3}{*}{1.2} & .05 & 42.63 & 35.46 & 32.59 & 36.91 & 33.37 & 31.62 & 29.72 & 26.74 \\
\hline & 0.1 & 43.04 & 35.83 & 32.95 & 37.30 & 33.74 & 31.98 & 30.07 & 27.06 \\
\hline & 0.2 & 44.75 & 37.39 & 34.45 & 38.93 & 35.28 & 33.47 & 31.51 & 28.40 \\
\hline \multirow[t]{5}{*}{1.5} & .05 & 8.07 & 5.62 & 4.64 & 5.53 & 4.51 & 4.08 & 3.65 & 3.06 \\
\hline & 0.1 & 8.20 & 5.72 & 4.72 & 5.63 & 4.60 & 4.17 & 3.73 & 3.12 \\
\hline & 0.2 & 8.75 & 6.14 & 5.10 & 6.08 & 4.99 & 4.52 & 4.06 & 3.40 \\
\hline & & \multirow[t]{2}{*}{ FSI } & \\
\hline & & & \multicolumn{7}{|c|}{ VSI } \\
\hline$\tau$ & $\gamma_{0}$ & \multicolumn{8}{|c|}{$n=15$} \\
\hline \multirow[t]{3}{*}{0.5} & .05 & 1.70 & 0.85 & 0.51 & 0.19 & 0.17 & 0.17 & 0.17 & 0.17 \\
\hline & 0.1 & 1.72 & 0.86 & 0.52 & 0.19 & 0.17 & 0.17 & 0.17 & 0.17 \\
\hline & 0.2 & 1.78 & 0.89 & 0.53 & 0.20 & 0.18 & 0.18 & 0.18 & 0.18 \\
\hline \multirow[t]{3}{*}{0.8} & .05 & 38.61 & 23.48 & 17.43 & 27.13 & 19.02 & 15.19 & 11.38 & 6.55 \\
\hline & 0.1 & 39.02 & 23.79 & 17.69 & 27.51 & 19.33 & 15.46 & 11.60 & 6.67 \\
\hline & 0.2 & 40.66 & 24.99 & 18.72 & 29.00 & 20.56 & 16.52 & 12.45 & 7.17 \\
\hline 0.9 & .05 & 121.77 & 95.85 & 85.48 & 108.64 & 94.68 & 86.02 & 75.11 & 53.88 \\
\hline & 0.1 & 122.53 & 96.59 & 86.21 & 109.41 & 95.45 & 86.77 & 75.83 & 54.50 \\
\hline & 0.2 & 125.46 & 99.45 & 89.05 & 112.41 & 98.42 & 89.69 & 78.65 & 56.94 \\
\hline 0.95 & 0.05 & 213.58 & 190.95 & 181.90 & 203.92 & 192.08 & 183.98 & 172.85 & 147.23 \\
\hline & 0.1 & 214.28 & 191.72 & 182.69 & 204.66 & 192.86 & 184.78 & 173.66 & 148.08 \\
\hline & 0.2 & 216.98 & 194.67 & 185.74 & 207.50 & 195.84 & 187.83 & 176.81 & 151.35 \\
\hline 1.05 & 0.05 & 135.94 & 122.83 & 117.59 & 128.07 & 121.19 & 117.20 & 112.34 & 103.03 \\
\hline & 0.1 & 136.80 & 123.70 & 118.45 & 128.95 & 122.07 & 118.08 & 113.21 & 103.88 \\
\hline & 0.2 & 140.23 & 127.13 & 121.89 & 132.41 & 125.53 & 121.53 & 116.65 & 107.25 \\
\hline 1.1 & .05 & 59.41 & 48.74 & 44.48 & 51.95 & 46.49 & 43.57 & 40.21 & 34.29 \\
\hline & 0.1 & 60.08 & 49.36 & 45.08 & 52.60 & 47.11 & 44.17 & 40.79 & 34.82 \\
\hline & 0.2 & 62.77 & 51.85 & 47.48 & 55.21 & 49.60 & 46.59 & 43.10 & 36.93 \\
\hline 1.2 & .05 & 16.93 & 11.81 & 9.76 & 12.35 & 9.97 & 8.87 & 7.72 & 5.95 \\
\hline & 0.1 & 17.23 & 12.05 & 9.98 & 12.61 & 10.20 & 9.08 & 7.90 & 6.10 \\
\hline & 0.2 & 18.46 & 13.03 & 10.85 & 13.68 & 11.13 & 9.93 & 8.68 & 6.73 \\
\hline 1.5 & .05 & 2.55 & 1.41 & 0.95 & 1.06 & 0.71 & 0.60 & 0.50 & 0.38 \\
\hline & 0.1 & 2.60 & 1.44 & 0.98 & 1.09 & 0.74 & 0.62 & 0.51 & 0.39 \\
\hline & 0.2 & 2.83 & 1.58 & 1.08 & 1.23 & 0.84 & 0.70 & 0.58 & 0.44 \\
\hline
\end{tabular}

Table 3: The out-of-control $A R L_{1}$ of the FSI SH- $\gamma$ chart and the out-of-control $A T S_{1}$ of the VSI SH- $\gamma^{2}$ charts for $\gamma_{0}=\{0.05,0.1,0.2\}, n=\{5,15\}, \tau=$ $\{0.5,0.8,0.9,0.95,1.05,1.1,1.2,1.5\}$. The first row shows the values of $\left(h_{S}, h_{L}\right)$. 


\begin{tabular}{|c|c|c|c|c|c|c|c|c|c|}
\hline \multirow{4}{*}{$\gamma_{0}$} & \multicolumn{9}{|c|}{$n=5$} \\
\hline & \multirow{3}{*}{$\eta$} & \multirow{3}{*}{ LCL } & \multirow{2}{*}{\multicolumn{6}{|c|}{ Downward CV chart }} & \multirow[b]{3}{*}{$(0.1,4.0)$} \\
\hline & & & & & & & & & \\
\hline & & & $(0.5,1.5)$ & $(0.3,1.7)$ & $(0.1,1.1)$ & $(0.1,1.3)$ & $(0.1,1.5)$ & $(0.1,1.9)$ & \\
\hline \multirow[t]{4}{*}{0.05} & 0.0 & 0.0001 & 0.0019 & 0.0019 & 0.0006 & 0.0011 & 0.0014 & 0.0019 & 0.0032 \\
\hline & 0.2 & 0.0001 & 0.0020 & 0.0020 & 0.0006 & 0.0011 & 0.0015 & 0.0020 & 0.0033 \\
\hline & 0.5 & 0.0001 & 0.0024 & 0.0024 & 0.0008 & 0.0014 & 0.0018 & 0.0024 & 0.0040 \\
\hline & 1.0 & 0.0002 & 0.0038 & 0.0038 & 0.0012 & 0.0022 & 0.0029 & 0.0038 & 0.0064 \\
\hline \multirow[t]{4}{*}{0.1} & 0.0 & 0.0003 & 0.0076 & 0.0076 & 0.0024 & 0.0044 & 0.0057 & 0.0076 & 0.0128 \\
\hline & 0.2 & 0.0004 & 0.0079 & 0.0079 & 0.0025 & 0.0046 & 0.0059 & 0.0079 & 0.0133 \\
\hline & 0.5 & 0.0004 & 0.0095 & 0.0095 & 0.0030 & 0.0055 & 0.0071 & 0.0095 & 0.0160 \\
\hline & 1.0 & 0.0007 & 0.0153 & 0.0153 & 0.0049 & 0.0087 & 0.0114 & 0.0153 & 0.0257 \\
\hline \multirow[t]{5}{*}{0.2} & 0.0 & 0.0013 & 0.0306 & 0.0306 & 0.0097 & 0.0174 & 0.0228 & 0.0306 & 0.0519 \\
\hline & 0.2 & 0.0014 & 0.0318 & 0.0318 & 0.0100 & 0.0181 & 0.0237 & 0.0318 & 0.0540 \\
\hline & 0.5 & 0.0017 & 0.0383 & 0.0383 & 0.0120 & 0.0217 & 0.0284 & 0.0383 & 0.0651 \\
\hline & 1.0 & 0.0026 & 0.0613 & 0.0613 & 0.0191 & 0.0345 & 0.0454 & 0.0613 & 0.1057 \\
\hline & \multicolumn{9}{|c|}{ Upward CV chart } \\
\hline \multirow[t]{2}{*}{$\gamma_{0}$} & \multirow[t]{2}{*}{$\eta$} & \multirow[t]{2}{*}{ UCL } & UWL & & & & & & \\
\hline & & & $(0.5,1.5)$ & $(0.3,1.7)$ & $(0.1,1.1)$ & $(0.1,1.3)$ & $(0.1,1.5)$ & $(0.1,1.9)$ & $(0.1,4.0)$ \\
\hline 0.05 & 0.0 & 0.0093 & 0.0019 & 0.0019 & 0.0044 & 0.0030 & 0.0025 & 0.0019 & 0.0010 \\
\hline & 0.2 & 0.0096 & 0.0020 & 0.0020 & 0.0046 & 0.0032 & 0.0026 & 0.0020 & 0.0011 \\
\hline & 0.5 & 0.0116 & 0.0024 & 0.0024 & 0.0055 & 0.0038 & 0.0031 & 0.0024 & 0.0013 \\
\hline & 1.0 & 0.0186 & 0.0038 & 0.0038 & 0.0088 & 0.0061 & 0.0050 & 0.0038 & 0.0021 \\
\hline 0.1 & 0.0 & 0.0378 & 0.0076 & 0.0076 & 0.0177 & 0.0122 & 0.0099 & 0.0076 & 0.0041 \\
\hline & 0.2 & 0.0393 & 0.0079 & 0.0079 & 0.0184 & 0.0127 & 0.0103 & 0.0079 & 0.0043 \\
\hline & 0.5 & 0.0475 & 0.0095 & 0.0095 & 0.0221 & 0.0153 & 0.0124 & 0.0095 & 0.0051 \\
\hline & 1.0 & 0.0774 & 0.0152 & 0.0152 & 0.0356 & 0.0245 & 0.0199 & 0.0152 & 0.0082 \\
\hline 0.2 & 0.0 & 0.1629 & 0.0304 & 0.0304 & 0.0725 & 0.0495 & 0.0400 & 0.0304 & 0.0163 \\
\hline & 0.2 & 0.1701 & 0.0317 & 0.0317 & 0.0755 & 0.0515 & 0.0416 & 0.0317 & 0.0170 \\
\hline & 0.5 & 0.2090 & 0.0381 & 0.0381 & 0.0914 & 0.0621 & 0.0501 & 0.0381 & 0.0204 \\
\hline & 1.0 & 0.3628 & 0.0610 & 0.0610 & 0.1500 & 0.1006 & 0.0807 & 0.0610 & 0.0324 \\
\hline & & & & & $n=$ & & & & \\
\hline & & & & & Downwa & CV chart & & & \\
\hline$\gamma_{0}$ & $\eta$ & LCL & LWL & & & & & & \\
\hline & & & $(0.5,1.5)$ & $(0.3,1.7)$ & $(0.1,1.1)$ & $(0.1,1.3)$ & $(0.1,1.5)$ & $(0.1,1.9)$ & $(0.1,4.0)$ \\
\hline 0.05 & 0.0 & 0.0006 & 0.0022 & 0.0022 & 0.0013 & 0.0017 & 0.0019 & 0.0022 & 0.0028 \\
\hline & 0.2 & 0.0006 & 0.0023 & 0.0023 & 0.0013 & 0.0017 & 0.0019 & 0.0023 & 0.0030 \\
\hline & 0.5 & 0.0007 & 0.0027 & 0.0027 & 0.0016 & 0.0021 & 0.0023 & 0.0027 & 0.0035 \\
\hline & 1.0 & 0.0012 & 0.0043 & 0.0043 & 0.0025 & 0.0033 & 0.0037 & 0.0043 & 0.0057 \\
\hline 0.1 & 0.0 & 0.0023 & 0.0087 & 0.0087 & 0.0051 & 0.0066 & 0.0075 & 0.0087 & 0.0114 \\
\hline & 0.2 & 0.0024 & 0.0090 & 0.0090 & 0.0053 & 0.0069 & 0.0078 & 0.0090 & 0.0118 \\
\hline & 0.5 & 0.0029 & 0.0108 & 0.0108 & 0.0063 & 0.0082 & 0.0094 & 0.0108 & 0.0142 \\
\hline & 1.0 & 0.0047 & 0.0173 & 0.0173 & 0.0101 & 0.0132 & 0.0150 & 0.0173 & 0.0228 \\
\hline 0.2 & 0.0 & 0.0092 & 0.0346 & 0.0346 & 0.0201 & 0.0262 & 0.0299 & 0.0346 & 0.0459 \\
\hline & 0.2 & 0.0096 & 0.0360 & 0.0360 & 0.0209 & 0.0273 & 0.0311 & 0.0360 & 0.0477 \\
\hline & 0.5 & 0.0114 & 0.0433 & 0.0433 & 0.0250 & 0.0327 & 0.0373 & 0.0433 & 0.0575 \\
\hline & 1.0 & 0.0180 & 0.0693 & 0.0693 & 0.0397 & 0.0521 & 0.0595 & 0.0693 & 0.0927 \\
\hline & & & & & Upwarc & CV chart & & & \\
\hline$\gamma_{0}$ & $\eta$ & UCL & UWL & & & & & & \\
\hline & & & $(0.5,1.5)$ & $(0.3,1.7)$ & $(0.1,1.1)$ & $(0.1,1.3)$ & $(0.1,1.5)$ & $(0.1,1.9)$ & $(0.1,4.0)$ \\
\hline 0.05 & 0.0 & 0.0054 & 0.0022 & 0.0022 & 0.0034 & 0.0028 & 0.0025 & 0.0022 & 0.0016 \\
\hline & 0.2 & 0.0056 & 0.0022 & 0.0022 & 0.0035 & 0.0029 & 0.0026 & 0.0022 & 0.0017 \\
\hline & 0.5 & 0.0067 & 0.0027 & 0.0027 & 0.0043 & 0.0035 & 0.0031 & 0.0027 & 0.0020 \\
\hline & 1.0 & 0.0108 & 0.0043 & 0.0043 & 0.0068 & 0.0055 & 0.0050 & 0.0043 & 0.0032 \\
\hline 0.1 & 0.0 & 0.0218 & 0.0086 & 0.0086 & 0.0137 & 0.0111 & 0.0099 & 0.0086 & 0.0064 \\
\hline & 0.2 & 0.0227 & 0.0090 & 0.0090 & 0.0142 & 0.0115 & 0.0103 & 0.0090 & 0.0067 \\
\hline & 0.5 & 0.0273 & 0.0108 & 0.0108 & 0.0171 & 0.0139 & 0.0124 & 0.0108 & 0.0080 \\
\hline & 1.0 & 0.0441 & 0.0173 & 0.0173 & 0.0274 & 0.0222 & 0.0199 & 0.0173 & 0.0128 \\
\hline 0.2 & 0.0 & 0.0904 & 0.0345 & 0.0345 & 0.0554 & 0.0447 & 0.0398 & 0.0345 & 0.0255 \\
\hline & 0.2 & 0.0942 & 0.0359 & 0.0359 & 0.0576 & 0.0465 & 0.0414 & 0.0359 & 0.0265 \\
\hline & 0.5 & 0.1144 & 0.0432 & 0.0432 & 0.0696 & 0.0560 & 0.0499 & 0.0432 & 0.0318 \\
\hline & 1.0 & 0.1900 & 0.0691 & 0.0691 & 0.1129 & 0.0902 & 0.0801 & 0.0691 & 0.0505 \\
\hline
\end{tabular}

Table 4: Control limits (boldfaced) and warning limits of VSI SH- $\gamma^{2}$ control charts in the presence of measurement error for different values of $\gamma_{0}, \eta, n$ and fixed $\theta=0.05, B=1, m=$ 


\begin{tabular}{|c|c|c|c|c|c|c|c|c|c|}
\hline \multirow{4}{*}{$\gamma_{0}$} & \multicolumn{9}{|c|}{$n=5$} \\
\hline & \multirow{3}{*}{$\theta$} & \multirow{3}{*}{ LCL } & \multicolumn{6}{|c|}{ Downward CV chart } & \multirow[b]{3}{*}{$(0.1,4.0)$} \\
\hline & & & LWL & & & & & & \\
\hline & & & $(0.5,1.5)$ & $(0.3,1.7)$ & $(0.1,1.1)$ & $(0.1,1.3)$ & $(0.1,1.5)$ & $(0.1,1.9)$ & \\
\hline \multirow[t]{3}{*}{0.05} & 0.0 & 0.0001 & 0.0023 & 0.0023 & 0.0007 & 0.0013 & 0.0017 & 0.0023 & 0.0038 \\
\hline & 0.03 & 0.0001 & 0.0021 & 0.0021 & 0.0007 & 0.0012 & 0.0016 & 0.0021 & 0.0036 \\
\hline & 0.05 & 0.0001 & 0.0021 & 0.0021 & 0.0007 & 0.0012 & 0.0015 & 0.0021 & 0.0034 \\
\hline \multirow[t]{3}{*}{0.1} & 0.0 & 0.0004 & 0.0091 & 0.0091 & 0.0029 & 0.0052 & 0.0068 & 0.0091 & 0.0152 \\
\hline & 0.03 & 0.0004 & 0.0086 & 0.0086 & 0.0027 & 0.0049 & 0.0064 & 0.0086 & 0.0143 \\
\hline & 0.05 & 0.0004 & 0.0082 & 0.0082 & 0.0026 & 0.0047 & 0.0062 & 0.0082 & 0.0138 \\
\hline \multirow[t]{4}{*}{0.2} & 0.0 & 0.0016 & 0.0364 & 0.0364 & 0.0114 & 0.0207 & 0.0271 & 0.0364 & 0.0619 \\
\hline & 0.03 & 0.0015 & 0.0343 & 0.0343 & 0.0108 & 0.0195 & 0.0255 & 0.0343 & 0.0583 \\
\hline & 0.05 & 0.0014 & 0.0330 & 0.0330 & 0.0104 & 0.0188 & 0.0246 & 0.0330 & 0.0560 \\
\hline & \multicolumn{9}{|c|}{ Upward CV chart } \\
\hline \multirow[t]{2}{*}{$\gamma_{0}$} & $\theta$ & UCL & UWL & & & & & & \\
\hline & & & $(0.5,1.5)$ & $(0.3,1.7)$ & $(0.1,1.1)$ & $(0.1,1.3)$ & $(0.1,1.5)$ & $(0.1,1.9)$ & $(0.1,4.0)$ \\
\hline \multirow[t]{3}{*}{0.05} & 0.0 & 0.0110 & 0.0023 & 0.0023 & 0.0052 & 0.0036 & 0.0029 & 0.0023 & 0.0012 \\
\hline & 0.03 & 0.0104 & 0.0021 & 0.0021 & 0.0049 & 0.0034 & 0.0028 & 0.0021 & 0.0012 \\
\hline & 0.05 & 0.0100 & 0.0020 & 0.0020 & 0.0047 & 0.0033 & 0.0027 & 0.0020 & 0.0011 \\
\hline \multirow[t]{3}{*}{0.1} & 0.0 & 0.0451 & 0.0090 & 0.0090 & 0.0210 & 0.0145 & 0.0118 & 0.0090 & 0.0049 \\
\hline & 0.03 & 0.0424 & 0.0085 & 0.0085 & 0.0198 & 0.0137 & 0.0111 & 0.0085 & 0.0046 \\
\hline & 0.05 & 0.0408 & 0.0082 & 0.0082 & 0.0191 & 0.0132 & 0.0107 & 0.0082 & 0.0044 \\
\hline \multirow[t]{5}{*}{0.2} & 0.0 & 0.1975 & 0.0362 & 0.0362 & 0.0867 & 0.0590 & 0.0476 & 0.0362 & 0.0194 \\
\hline & 0.03 & 0.1848 & 0.0341 & 0.0341 & 0.0815 & 0.0556 & 0.0449 & 0.0341 & 0.0183 \\
\hline & 0.05 & 0.1771 & 0.0328 & 0.0328 & 0.0784 & 0.0534 & 0.0431 & 0.0328 & 0.0176 \\
\hline & \multicolumn{9}{|c|}{$n=15$} \\
\hline & \multicolumn{9}{|c|}{ Downward CV chart } \\
\hline \multirow[t]{2}{*}{$\gamma_{0}$} & $\theta$ & LCL & LWL & & & & & & \\
\hline & & & $(0.5,1.5)$ & $(0.3,1.7)$ & $(0.1,1.1)$ & $(0.1,1.3)$ & $(0.1,1.5)$ & $(0.1,1.9)$ & $(0.1,4.0)$ \\
\hline \multirow[t]{3}{*}{0.05} & 0.0 & 0.0007 & 0.0026 & 0.0026 & 0.0015 & 0.0020 & 0.0022 & 0.0026 & 0.0034 \\
\hline & 0.03 & 0.0007 & 0.0024 & 0.0024 & 0.0014 & 0.0018 & 0.0021 & 0.0024 & 0.0032 \\
\hline & 0.05 & 0.0006 & 0.0023 & 0.0023 & 0.0014 & 0.0018 & 0.0020 & 0.0023 & 0.0031 \\
\hline \multirow[t]{3}{*}{0.1} & 0.0 & 0.0028 & 0.0103 & 0.0103 & 0.0060 & 0.0078 & 0.0089 & 0.0103 & 0.0135 \\
\hline & 0.03 & 0.0026 & 0.0097 & 0.0097 & 0.0057 & 0.0074 & 0.0084 & 0.0097 & 0.0128 \\
\hline & 0.05 & 0.0025 & 0.0093 & 0.0093 & 0.0055 & 0.0071 & 0.0081 & 0.0093 & 0.0123 \\
\hline 0.2 & 0.0 & 0.0109 & 0.0412 & 0.0412 & 0.0238 & 0.0312 & 0.0355 & 0.0412 & 0.0546 \\
\hline & 0.03 & 0.0103 & 0.0388 & 0.0388 & 0.0225 & 0.0294 & 0.0335 & 0.0388 & 0.0515 \\
\hline & 0.05 & 0.0099 & 0.0374 & 0.0374 & 0.0216 & 0.0283 & 0.0322 & 0.0374 & 0.0495 \\
\hline & & & & & Upward & CV chart & & & \\
\hline$\gamma_{0}$ & $\theta$ & UCL & UWL & & & & & & \\
\hline & & & $(0.5,1.5)$ & $(0.3,1.7)$ & $(0.1,1.1)$ & $(0.1,1.3)$ & $(0.1,1.5)$ & $(0.1,1.9)$ & $(0.1,4.0)$ \\
\hline 0.05 & 0.0 & 0.0064 & 0.0026 & 0.0026 & 0.0040 & 0.0033 & 0.0029 & 0.0026 & 0.0019 \\
\hline & 0.03 & 0.0060 & 0.0024 & 0.0024 & 0.0038 & 0.0031 & 0.0028 & 0.0024 & 0.0018 \\
\hline & 0.05 & 0.0058 & 0.0023 & 0.0023 & 0.0037 & 0.0030 & 0.0027 & 0.0023 & 0.0017 \\
\hline 0.1 & 0.0 & 0.0259 & 0.0103 & 0.0103 & 0.0162 & 0.0132 & 0.0118 & 0.0103 & 0.0076 \\
\hline & 0.03 & 0.0244 & 0.0097 & 0.0097 & 0.0153 & 0.0124 & 0.0111 & 0.0097 & 0.0072 \\
\hline & 0.05 & 0.0235 & 0.0093 & 0.0093 & 0.0147 & 0.0120 & 0.0107 & 0.0093 & 0.0069 \\
\hline 0.2 & 0.0 & 0.1085 & 0.0411 & 0.0411 & 0.0661 & 0.0532 & 0.0474 & 0.0411 & 0.0302 \\
\hline & 0.03 & 0.1019 & 0.0387 & 0.0387 & 0.0622 & 0.0501 & 0.0447 & 0.0387 & 0.0285 \\
\hline & 0.05 & 0.0978 & 0.0373 & 0.0373 & 0.0598 & 0.0482 & 0.0430 & 0.0373 & 0.0274 \\
\hline
\end{tabular}

Table 5: Control limits (boldfaced) and warning limits of VSI SH- $\gamma^{2}$ control charts in the presence of measurement error for different values of $\gamma_{0}, \theta, n$ and fixed $\eta=0.28, B=1, m=$ 1. 


\begin{tabular}{|c|c|c|c|c|c|c|c|c|c|}
\hline \multirow{4}{*}{$\gamma_{0}$} & \multicolumn{9}{|c|}{$n=5$} \\
\hline & \multirow{3}{*}{$B$} & \multicolumn{8}{|c|}{ Downward CV chart } \\
\hline & & LCL & LWL & & & & & & \\
\hline & & & $(0.5,1.5)$ & $(0.3,1.7)$ & $(0.1,1.1)$ & $(0.1,1.3)$ & $(0.1,1.5)$ & $(0.1,1.9)$ & $(0.1,4.0)$ \\
\hline \multirow[t]{3}{*}{0.05} & 2 & 0.0001 & 0.0021 & 0.0021 & 0.0007 & 0.0012 & 0.0016 & 0.0021 & 0.0035 \\
\hline & 3 & 0.0001 & 0.0021 & 0.0021 & 0.0007 & 0.0012 & 0.0016 & 0.0021 & 0.0035 \\
\hline & 5 & 0.0001 & 0.0021 & 0.0021 & 0.0007 & 0.0012 & 0.0016 & 0.0021 & 0.0035 \\
\hline \multirow[t]{3}{*}{0.1} & 2 & 0.0004 & 0.0085 & 0.0085 & 0.0027 & 0.0049 & 0.0064 & 0.0085 & 0.0142 \\
\hline & 3 & 0.0004 & 0.0084 & 0.0084 & 0.0027 & 0.0048 & 0.0063 & 0.0084 & 0.0141 \\
\hline & 5 & 0.0004 & 0.0084 & 0.0084 & 0.0027 & 0.0048 & 0.0063 & 0.0084 & 0.0141 \\
\hline \multirow[t]{4}{*}{0.2} & 2 & 0.0015 & 0.0341 & 0.0341 & 0.0107 & 0.0194 & 0.0253 & 0.0341 & 0.0578 \\
\hline & 3 & 0.0015 & 0.0338 & 0.0338 & 0.0106 & 0.0192 & 0.0251 & 0.0338 & 0.0574 \\
\hline & 5 & 0.0015 & 0.0337 & 0.0337 & 0.0106 & 0.0192 & 0.0251 & 0.0337 & 0.0572 \\
\hline & \multicolumn{9}{|c|}{ Upward CV chart } \\
\hline \multirow[t]{2}{*}{$\gamma_{0}$} & $B$ & UCL & UWL & & & & & & \\
\hline & & & $(0.5,1.5)$ & $(0.3,1.7)$ & $(0.1,1.1)$ & $(0.1,1.3)$ & $(0.1,1.5)$ & $(0.1,1.9)$ & $(0.1,4.0)$ \\
\hline \multirow[t]{3}{*}{0.05} & 2 & 0.0103 & 0.0021 & 0.0021 & 0.0049 & 0.0034 & 0.0028 & 0.0021 & 0.0011 \\
\hline & 3 & 0.0102 & 0.0021 & 0.0021 & 0.0048 & 0.0034 & 0.0027 & 0.0021 & 0.0011 \\
\hline & 5 & 0.0102 & 0.0021 & 0.0021 & 0.0048 & 0.0034 & 0.0027 & 0.0021 & 0.0011 \\
\hline \multirow[t]{3}{*}{0.1} & 2 & 0.0421 & 0.0085 & 0.0085 & 0.0197 & 0.0136 & 0.0110 & 0.0085 & 0.0046 \\
\hline & 3 & 0.0418 & 0.0084 & 0.0084 & 0.0195 & 0.0135 & 0.0110 & 0.0084 & 0.0045 \\
\hline & 5 & 0.0417 & 0.0084 & 0.0084 & 0.0195 & 0.0135 & 0.0109 & 0.0084 & 0.0045 \\
\hline \multirow[t]{5}{*}{0.2} & 2 & 0.1834 & 0.0339 & 0.0339 & 0.0810 & 0.0552 & 0.0445 & 0.0339 & 0.0181 \\
\hline & 3 & 0.1819 & 0.0336 & 0.0336 & 0.0803 & 0.0548 & 0.0442 & 0.0336 & 0.0180 \\
\hline & 5 & 0.1813 & 0.0335 & 0.0335 & 0.0801 & 0.0546 & 0.0441 & 0.0335 & 0.0180 \\
\hline & \multicolumn{9}{|c|}{$n=15$} \\
\hline & & & & & Downwa & CV chart & & & \\
\hline \multirow[t]{2}{*}{$\gamma_{0}$} & $B$ & LCL & LWL & & & & & & \\
\hline & & & $(0.5,1.5)$ & $(0.3,1.7)$ & $(0.1,1.1)$ & $(0.1,1.3)$ & $(0.1,1.5)$ & $(0.1,1.9)$ & $(0.1,4.0)$ \\
\hline \multirow[t]{3}{*}{0.05} & 2 & 0.0007 & 0.0024 & 0.0024 & 0.0014 & 0.0018 & 0.0021 & 0.0024 & 0.0032 \\
\hline & 3 & 0.0006 & 0.0024 & 0.0024 & 0.0014 & 0.0018 & 0.0021 & 0.0024 & 0.0031 \\
\hline & 5 & 0.0006 & 0.0024 & 0.0024 & 0.0014 & 0.0018 & 0.0021 & 0.0024 & 0.0031 \\
\hline \multirow[t]{3}{*}{0.1} & 2 & 0.0026 & 0.0096 & 0.0096 & 0.0056 & 0.0073 & 0.0083 & 0.0096 & 0.0127 \\
\hline & 3 & 0.0026 & 0.0096 & 0.0096 & 0.0056 & 0.0073 & 0.0083 & 0.0096 & 0.0126 \\
\hline & 5 & 0.0026 & 0.0095 & 0.0095 & 0.0056 & 0.0073 & 0.0082 & 0.0095 & 0.0125 \\
\hline \multirow[t]{4}{*}{0.2} & 2 & 0.0102 & 0.0386 & 0.0386 & 0.0223 & 0.0292 & 0.0332 & 0.0386 & 0.0511 \\
\hline & 3 & 0.0101 & 0.0383 & 0.0383 & 0.0221 & 0.0290 & 0.0330 & 0.0383 & 0.0507 \\
\hline & 5 & 0.0101 & 0.0382 & 0.0382 & 0.0221 & 0.0289 & 0.0329 & 0.0382 & 0.0506 \\
\hline & \multicolumn{9}{|c|}{ Upward CV chart } \\
\hline \multirow[t]{2}{*}{$\gamma_{0}$} & $B$ & UCL & UWL & & & & & & \\
\hline & & & $(0.5,1.5)$ & $(0.3,1.7)$ & $(0.1,1.1)$ & $(0.1,1.3)$ & $(0.1,1.5)$ & $(0.1,1.9)$ & $(0.1,4.0)$ \\
\hline 0.05 & 2 & 0.0060 & 0.0024 & 0.0024 & 0.0038 & 0.0031 & 0.0028 & 0.0024 & 0.0018 \\
\hline & 3 & 0.0060 & 0.0024 & 0.0024 & 0.0038 & 0.0031 & 0.0027 & 0.0024 & 0.0018 \\
\hline & 5 & 0.0059 & 0.0024 & 0.0024 & 0.0037 & 0.0030 & 0.0027 & 0.0024 & 0.0018 \\
\hline 0.1 & 2 & 0.0243 & 0.0096 & 0.0096 & 0.0152 & 0.0123 & 0.0110 & 0.0096 & 0.0071 \\
\hline & 3 & 0.0241 & 0.0095 & 0.0095 & 0.0151 & 0.0123 & 0.0110 & 0.0095 & 0.0071 \\
\hline & 5 & 0.0240 & 0.0095 & 0.0095 & 0.0150 & 0.0122 & 0.0109 & 0.0095 & 0.0070 \\
\hline 0.2 & 2 & 0.1011 & 0.0385 & 0.0385 & 0.0618 & 0.0498 & 0.0444 & 0.0385 & 0.0283 \\
\hline & 3 & 0.1004 & 0.0382 & 0.0382 & 0.0613 & 0.0494 & 0.0440 & 0.0382 & 0.0281 \\
\hline & 5 & 0.1000 & 0.0381 & 0.0381 & 0.0611 & 0.0493 & 0.0439 & 0.0381 & 0.0280 \\
\hline
\end{tabular}

Table 6: Control limits (boldfaced) and warning limits of VSI SH- $\gamma^{2}$ control charts in the presence of measurement error for different values of $\gamma_{0}, B, n$ and fixed $\eta=0.28, \theta=$ $0.01, m=1$. 


\begin{tabular}{|c|c|c|c|c|c|c|c|c|c|}
\hline \multirow{4}{*}{$\gamma_{0}$} & \multicolumn{9}{|c|}{$n=5$} \\
\hline & \multirow{3}{*}{$m$} & \multicolumn{8}{|c|}{ Downward CV chart } \\
\hline & & LCL & LWL & & & & & & \\
\hline & & & $(0.5,1.5)$ & $(0.3,1.7)$ & $(0.1,1.1)$ & $(0.1,1.3)$ & $(0.1,1.5)$ & $(0.1,1.9)$ & $(0.1,4.0)$ \\
\hline \multirow[t]{3}{*}{0.05} & 1 & 0.0001 & 0.0021 & 0.0021 & 0.0007 & 0.0012 & 0.0015 & 0.0021 & 0.0034 \\
\hline & 5 & 0.0001 & 0.0019 & 0.0019 & 0.0006 & 0.0011 & 0.0015 & 0.0019 & 0.0032 \\
\hline & 10 & 0.0001 & 0.0019 & 0.0019 & 0.0006 & 0.0011 & 0.0014 & 0.0019 & 0.0032 \\
\hline \multirow[t]{3}{*}{0.1} & 1 & 0.0004 & 0.0082 & 0.0082 & 0.0026 & 0.0047 & 0.0062 & 0.0082 & 0.0138 \\
\hline & 5 & 0.0003 & 0.0078 & 0.0078 & 0.0025 & 0.0044 & 0.0058 & 0.0078 & 0.0130 \\
\hline & 10 & 0.0003 & 0.0077 & 0.0077 & 0.0025 & 0.0044 & 0.0058 & 0.0077 & 0.0129 \\
\hline \multirow[t]{4}{*}{0.2} & 1 & 0.0014 & 0.0330 & 0.0330 & 0.0104 & 0.0188 & 0.0246 & 0.0330 & 0.0560 \\
\hline & 5 & 0.0014 & 0.0311 & 0.0311 & 0.0098 & 0.0177 & 0.0231 & 0.0311 & 0.0527 \\
\hline & 10 & 0.0013 & 0.0308 & 0.0308 & 0.0097 & 0.0175 & 0.0230 & 0.0308 & 0.0523 \\
\hline & \multicolumn{9}{|c|}{ Upward CV chart } \\
\hline \multirow[t]{2}{*}{$\gamma_{0}$} & \multirow[t]{2}{*}{$m$} & \multirow[t]{2}{*}{ UCL } & UWL & & & & & & \\
\hline & & & $(0.5,1.5)$ & $(0.3,1.7)$ & $(0.1,1.1)$ & $(0.1,1.3)$ & $(0.1,1.5)$ & $(0.1,1.9)$ & $(0.1,4.0)$ \\
\hline \multirow[t]{3}{*}{0.05} & 1 & 0.0100 & 0.0020 & 0.0020 & 0.0047 & 0.0033 & 0.0027 & 0.0020 & 0.0011 \\
\hline & 5 & 0.0094 & 0.0019 & 0.0019 & 0.0045 & 0.0031 & 0.0025 & 0.0019 & 0.0010 \\
\hline & 10 & 0.0093 & 0.0019 & 0.0019 & 0.0044 & 0.0031 & 0.0025 & 0.0019 & 0.0010 \\
\hline \multirow[t]{3}{*}{0.1} & 1 & 0.0408 & 0.0082 & 0.0082 & 0.0191 & 0.0132 & 0.0107 & 0.0082 & 0.0044 \\
\hline & 5 & 0.0384 & 0.0077 & 0.0077 & 0.0179 & 0.0124 & 0.0101 & 0.0077 & 0.0042 \\
\hline & 10 & 0.0381 & 0.0077 & 0.0077 & 0.0178 & 0.0123 & 0.0100 & 0.0077 & 0.0041 \\
\hline \multirow[t]{5}{*}{0.2} & 1 & 0.1771 & 0.0328 & 0.0328 & 0.0784 & 0.0534 & 0.0431 & 0.0328 & 0.0176 \\
\hline & 5 & 0.1657 & 0.0309 & 0.0309 & 0.0736 & 0.0503 & 0.0406 & 0.0309 & 0.0166 \\
\hline & 10 & 0.1643 & 0.0307 & 0.0307 & 0.0731 & 0.0499 & 0.0403 & 0.0307 & 0.0164 \\
\hline & \multicolumn{9}{|c|}{$n=15$} \\
\hline & & & & & Downwa & CV chart & & & \\
\hline \multirow[t]{2}{*}{$\gamma_{0}$} & $m$ & LCL & LWL & & & & & & \\
\hline & & & $(0.5,1.5)$ & $(0.3,1.7)$ & $(0.1,1.1)$ & $(0.1,1.3)$ & $(0.1,1.5)$ & $(0.1,1.9)$ & $(0.1,4.0)$ \\
\hline \multirow[t]{3}{*}{0.05} & 1 & 0.0006 & 0.0023 & 0.0023 & 0.0014 & 0.0018 & 0.0020 & 0.0023 & 0.0031 \\
\hline & 5 & 0.0006 & 0.0022 & 0.0022 & 0.0013 & 0.0017 & 0.0019 & 0.0022 & 0.0029 \\
\hline & 10 & 0.0006 & 0.0022 & 0.0022 & 0.0013 & 0.0017 & 0.0019 & 0.0022 & 0.0029 \\
\hline \multirow[t]{3}{*}{0.1} & 1 & 0.0025 & 0.0093 & 0.0093 & 0.0055 & 0.0071 & 0.0081 & 0.0093 & 0.0123 \\
\hline & 5 & 0.0024 & 0.0088 & 0.0088 & 0.0051 & 0.0067 & 0.0076 & 0.0088 & 0.0116 \\
\hline & 10 & 0.0024 & 0.0087 & 0.0087 & 0.0051 & 0.0066 & 0.0075 & 0.0087 & 0.0115 \\
\hline \multirow[t]{4}{*}{0.2} & 1 & 0.0099 & 0.0374 & 0.0374 & 0.0216 & 0.0283 & 0.0322 & 0.0374 & 0.0495 \\
\hline & 5 & 0.0093 & 0.0352 & 0.0352 & 0.0204 & 0.0266 & 0.0303 & 0.0352 & 0.0466 \\
\hline & 10 & 0.0093 & 0.0349 & 0.0349 & 0.0202 & 0.0264 & 0.0301 & 0.0349 & 0.0462 \\
\hline & & & & & Upwarc & CV chart & & & \\
\hline$\gamma_{0}$ & $m$ & UCL & UWL & & & & & & \\
\hline & & & $(0.5,1.5)$ & $(0.3,1.7)$ & $(0.1,1.1)$ & $(0.1,1.3)$ & $(0.1,1.5)$ & $(0.1,1.9)$ & $(0.1,4.0)$ \\
\hline 0.05 & 1 & 0.0058 & 0.0023 & 0.0023 & 0.0037 & 0.0030 & 0.0027 & 0.0023 & 0.0017 \\
\hline & 5 & 0.0055 & 0.0022 & 0.0022 & 0.0035 & 0.0028 & 0.0025 & 0.0022 & 0.0016 \\
\hline & 10 & 0.0054 & 0.0022 & 0.0022 & 0.0034 & 0.0028 & 0.0025 & 0.0022 & 0.0016 \\
\hline 0.1 & 1 & 0.0235 & 0.0093 & 0.0093 & 0.0147 & 0.0120 & 0.0107 & 0.0093 & 0.0069 \\
\hline & 5 & 0.0221 & 0.0088 & 0.0088 & 0.0139 & 0.0113 & 0.0101 & 0.0088 & 0.0065 \\
\hline & 10 & 0.0219 & 0.0087 & 0.0087 & 0.0138 & 0.0112 & 0.0100 & 0.0087 & 0.0064 \\
\hline 0.2 & 1 & 0.0978 & 0.0373 & 0.0373 & 0.0598 & 0.0482 & 0.0430 & 0.0373 & 0.0274 \\
\hline & 5 & 0.0919 & 0.0351 & 0.0351 & 0.0563 & 0.0454 & 0.0405 & 0.0351 & 0.0258 \\
\hline & 10 & 0.0911 & 0.0348 & 0.0348 & 0.0558 & 0.0450 & 0.0401 & 0.0348 & 0.0257 \\
\hline
\end{tabular}

Table 7: Control limits (boldfaced) and warning limits of VSI SH- $\gamma^{2}$ control charts in the presence of measurement error for different values of $\gamma_{0}, m, n$ and fixed $\eta=0.28, \theta=$ $0.01, B=1$. 


\begin{tabular}{|c|c|c|c|}
\hline 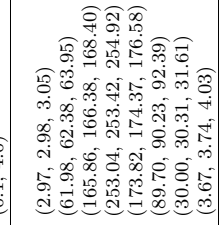 & 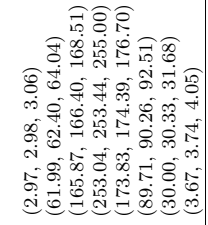 & 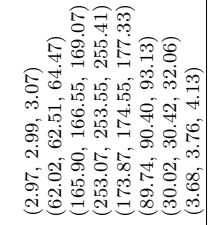 & 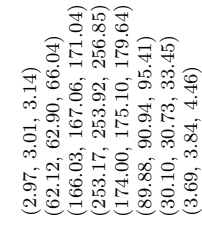 \\
\hline 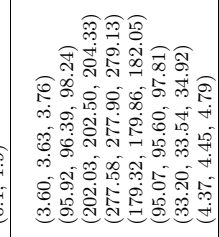 & 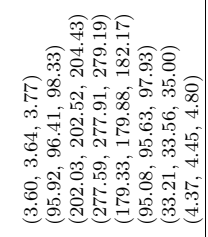 & 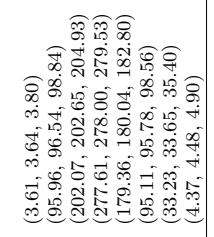 & 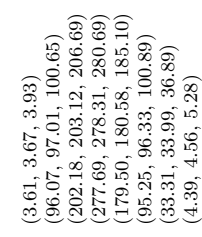 \\
\hline 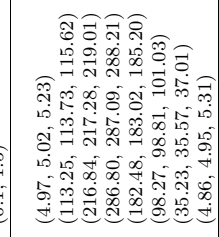 & 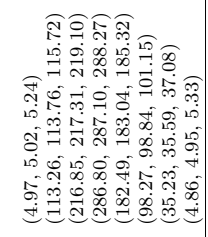 & 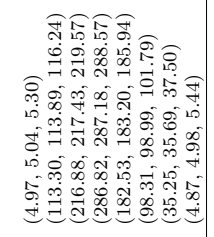 & 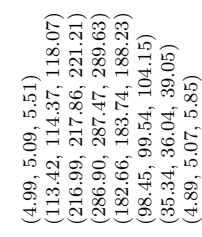 \\
\hline 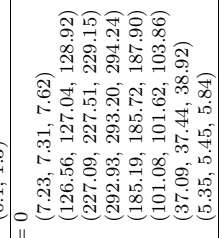 & 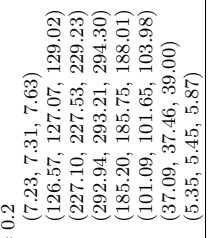 & 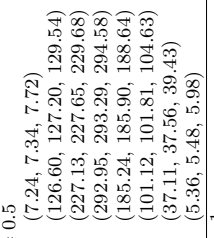 & 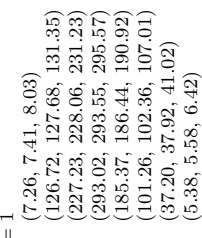 \\
\hline 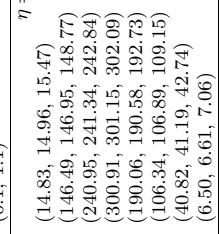 & 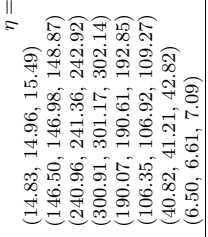 & 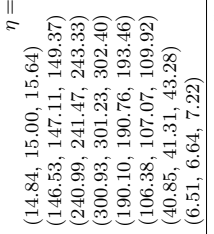 & 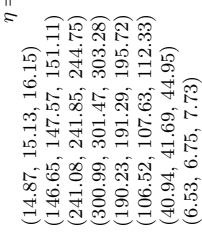 \\
\hline 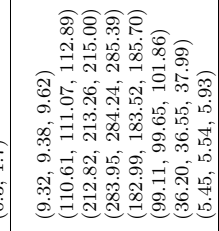 & 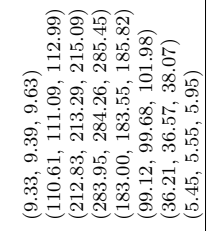 & 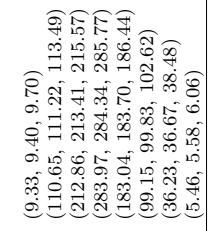 & 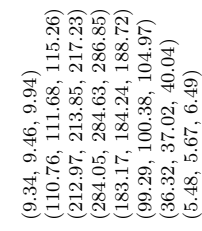 \\
\hline 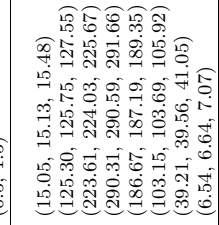 & 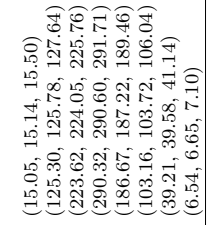 & 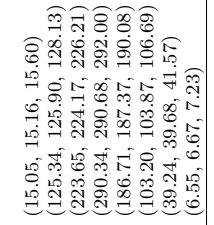 & \\
\hline 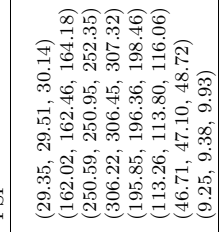 & 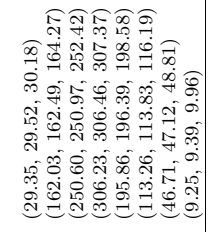 & 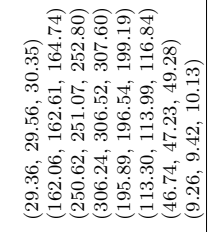 & 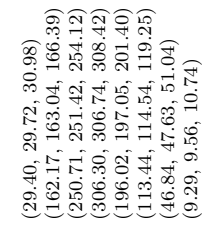 \\
\hline & & & \\
\hline
\end{tabular}

Table 8: The out-of-control $A R L_{1}$ of the FSI SH- $\gamma$ chart and the out-of-control $A T S_{1}$ of the VSI SH- $\gamma^{2}$ charts in the presence of measurement errors for different values of $\eta, \tau, n$, fixed $\theta=0.05, B=1, m=1, \gamma_{0}=0.05$ (left side), $\gamma_{0}=0.1$ (middle), $\gamma_{0}=0.2$ (right side) and sample size $n=5$; the first row shows the values of $\left(h_{S}, h_{L}\right)$. 


\begin{tabular}{|c|c|c|c|}
\hline 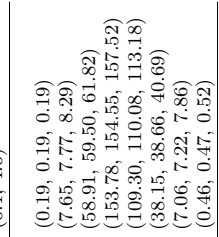 & 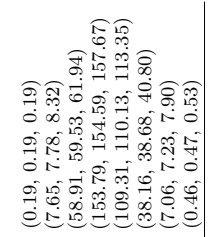 & 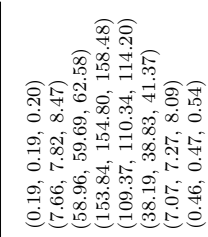 & 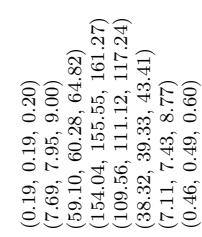 \\
\hline 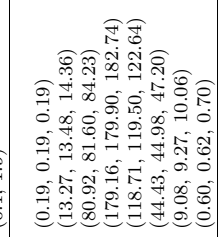 & 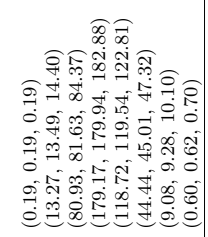 & 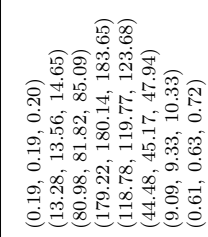 & 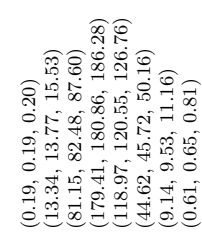 \\
\hline 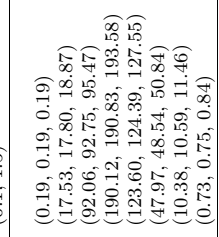 & 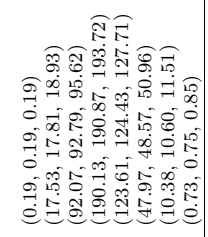 & 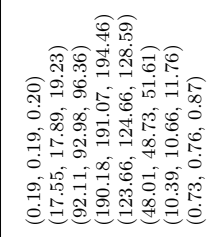 & 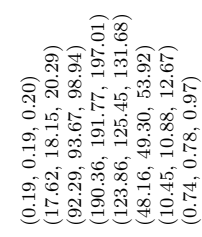 \\
\hline 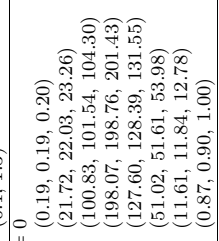 & 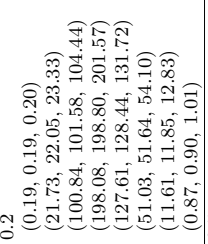 & 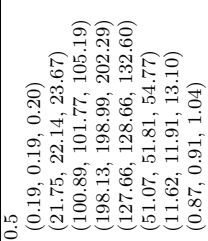 & 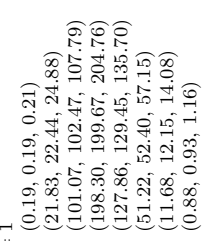 \\
\hline 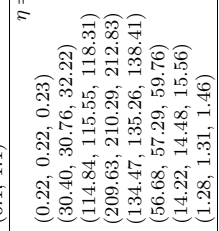 & 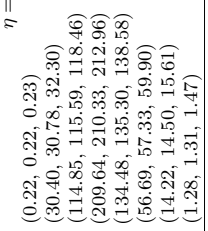 & 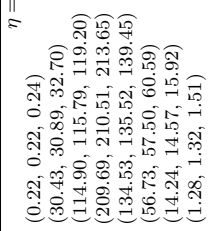 & 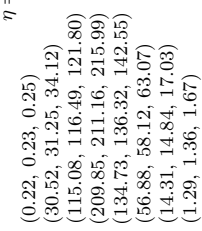 \\
\hline 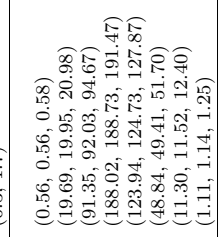 & 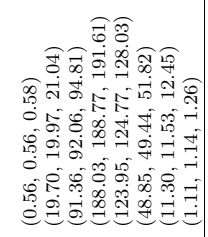 & 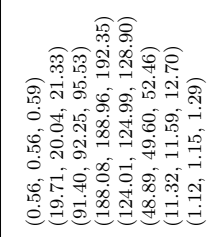 & 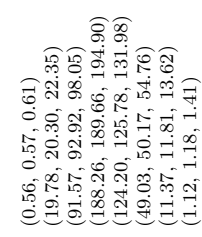 \\
\hline 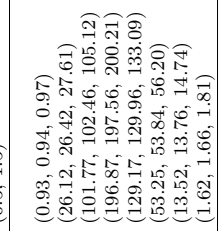 & 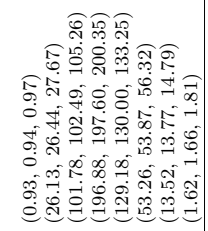 & 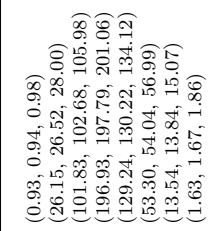 & 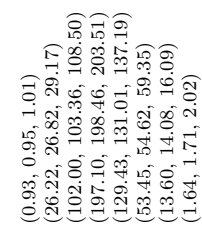 \\
\hline 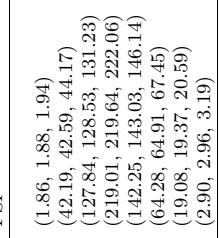 & 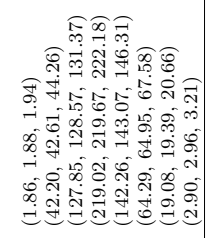 & 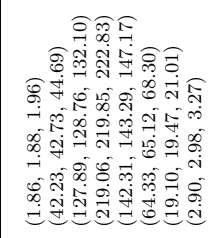 & 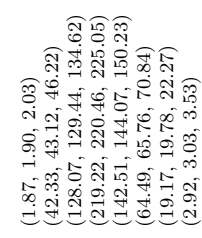 \\
\hline & & & \\
\hline
\end{tabular}

Table 9: The out-of-control $A R L_{1}$ of the FSI SH- $\gamma$ chart and the out-of-control $A T S_{1}$ of the VSI SH- $\gamma^{2}$ charts in the presence of measurement errors for different values of $\eta, \tau, n$, fixed $\theta=0.05, B=1, m=1, \gamma_{0}=0.05$ (left side), $\gamma_{0}=0.1$ (middle), $\gamma_{0}=0.2$ (right side) and sample size $n=15$; the first row shows the values of $\left(h_{S}, h_{L}\right)$. 


\begin{tabular}{|c|c|c|c|c|c|c|c|}
\hline & 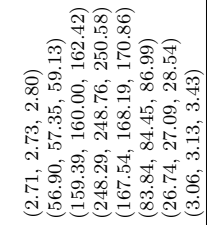 & 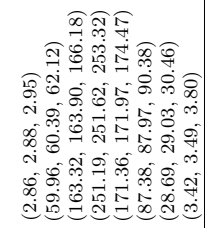 & 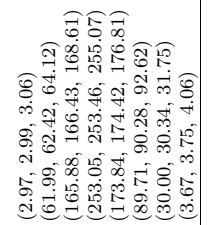 & $\mid \begin{array}{l}\vec{b} \\
\dot{+} \\
\dot{e}\end{array}$ & 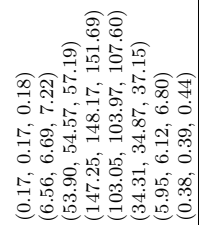 & 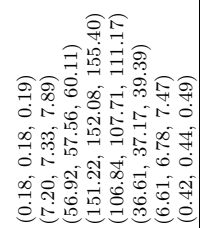 & 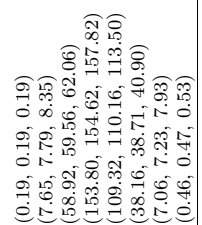 \\
\hline & 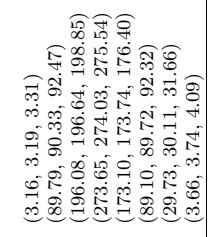 & 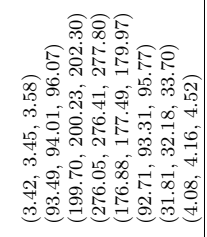 & 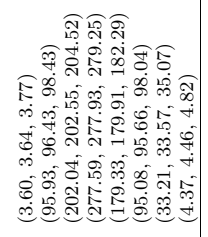 & & 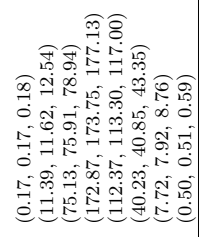 & 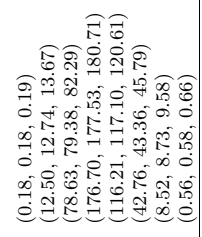 & 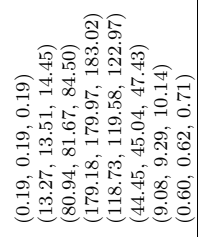 \\
\hline & 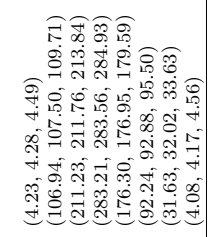 & 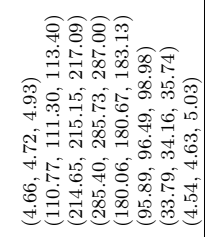 & 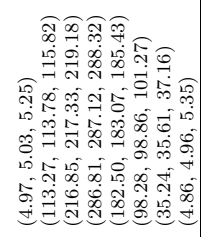 & 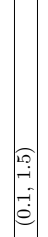 & 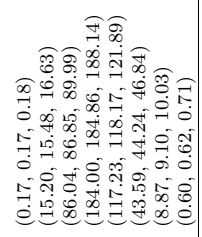 & 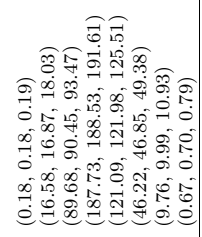 & 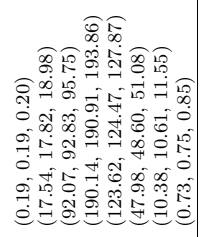 \\
\hline & 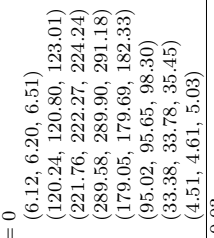 & 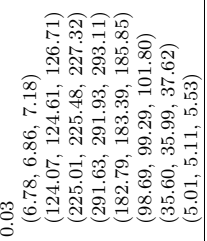 & 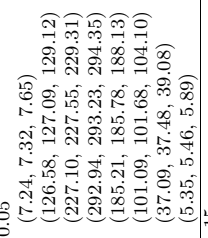 & & 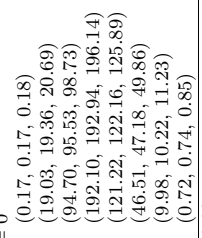 & 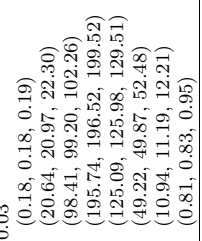 & 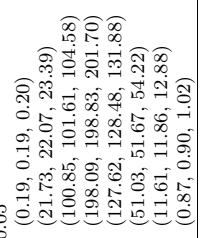 \\
\hline & 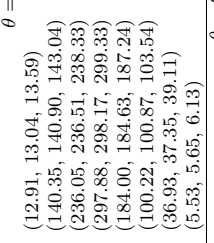 & 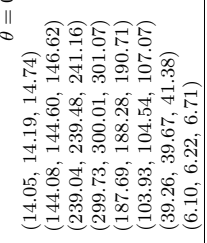 & 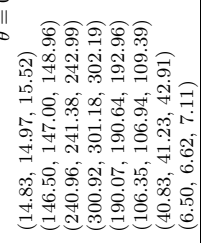 & $\begin{array}{l}7 \\
\vec{\theta} \\
\vec{\theta}\end{array}$ & 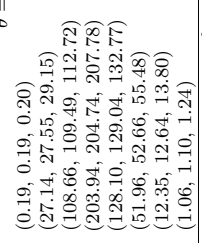 & 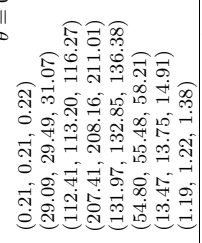 & 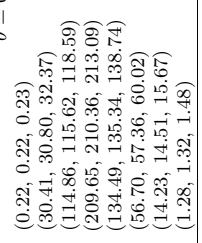 \\
\hline & 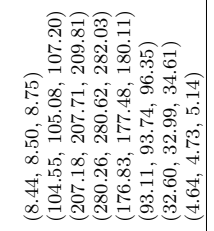 & 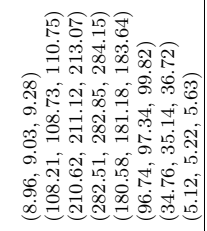 & 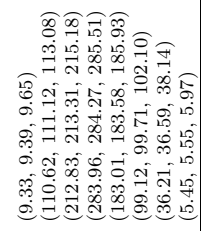 & & 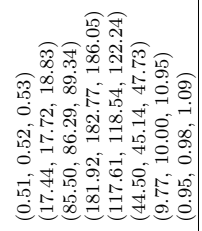 & 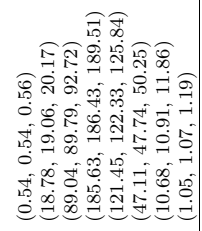 & 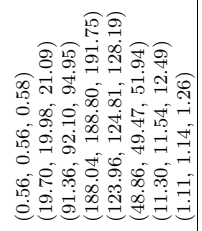 \\
\hline & 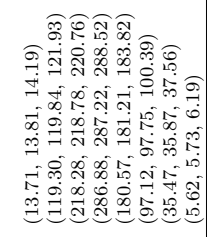 & 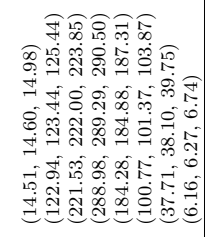 & 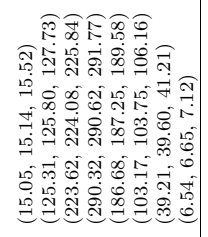 & & 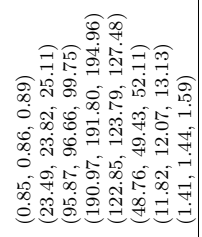 & 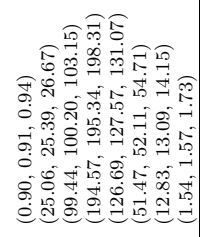 & 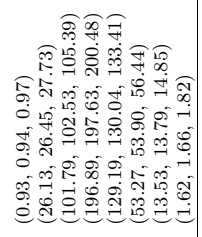 \\
\hline & 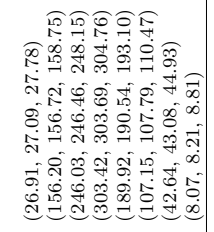 & 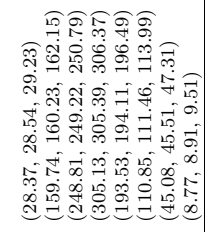 & 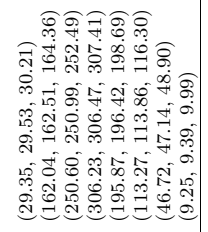 & & 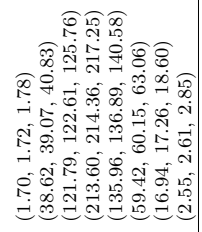 & 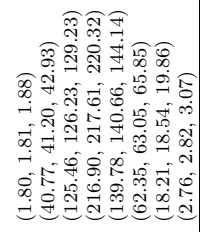 & 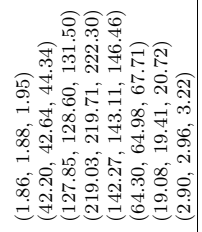 \\
\hline & & & & & & & \\
\hline
\end{tabular}

Table 10: The out-of-control $A R L_{1}$ of the FSI SH- $\gamma$ chart and the out-of-control $A T S_{1}$ of the VSI SH- $\gamma^{2}$ charts in the presence of measurement errors for different values of $\theta, \tau, n$, fixed $\eta=0.28, B=1, m=1, \gamma_{0}=0.05$ (left side), $\gamma_{0}=0.1$ (middle) and $\gamma_{0}=0.2$ (right side); the first row shows the values of $\left(h_{S}, h_{L}\right)$. 


\begin{tabular}{|c|c|c|c|c|c|c|c|}
\hline & 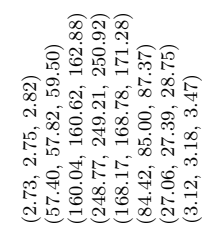 & 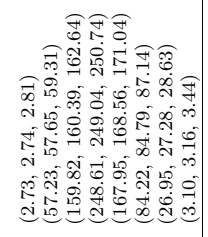 & 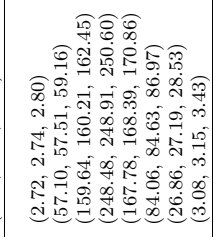 & & 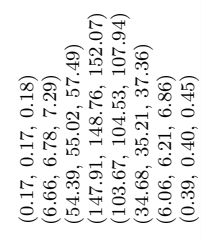 & 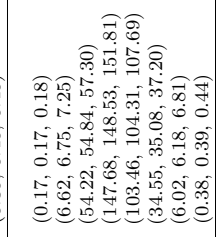 & 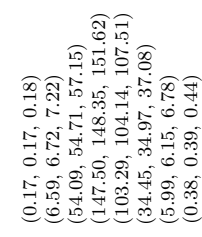 \\
\hline & 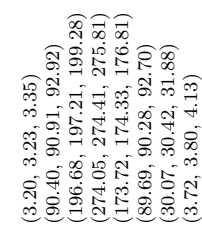 & 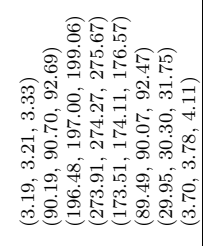 & 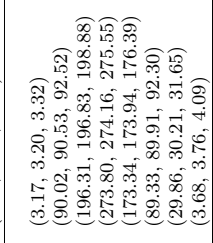 & & 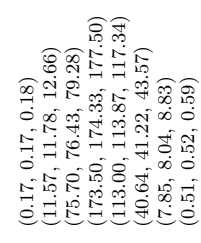 & 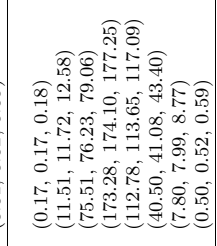 & 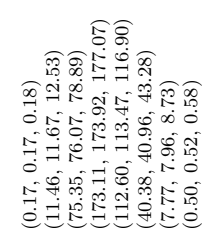 \\
\hline & 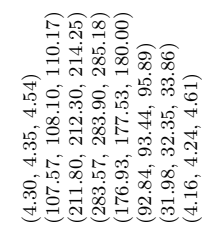 & 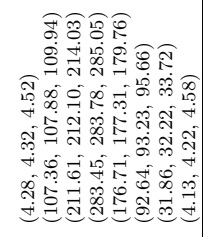 & 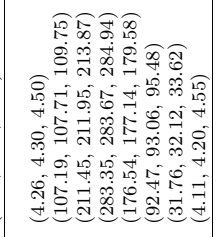 & $=$ & 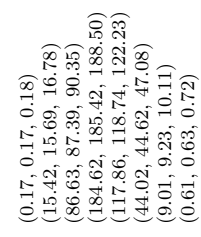 & 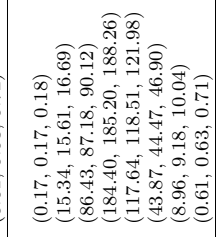 & \\
\hline & 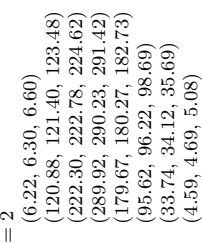 & 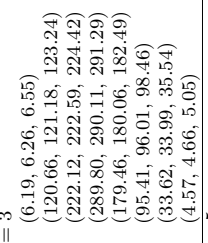 & 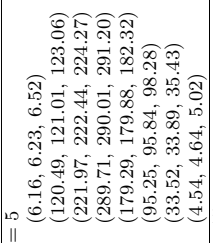 & 霍 & 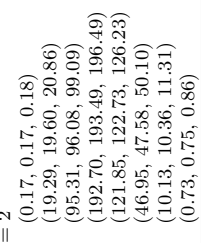 & 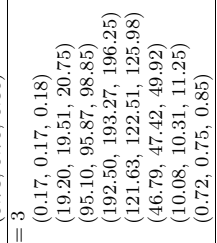 & $\begin{array}{l}\infty \\
0 \\
0 \\
1=0 \\
0 \\
0 \\
1=0\end{array}$ \\
\hline & 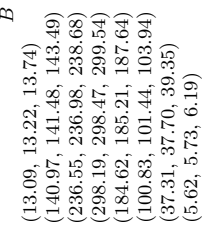 & 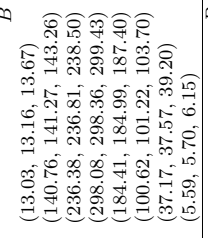 & 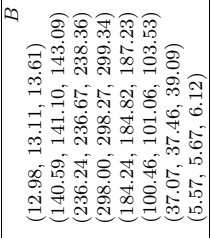 & $=$ & 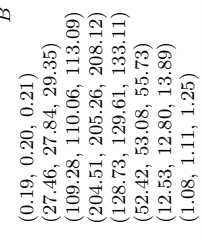 & . & $\begin{array}{l}0 \\
0 \\
0 \\
0 \\
0 \\
0 \\
0 \\
0 \\
0 \\
0 \\
0 \\
0 \\
0\end{array}$ \\
\hline & 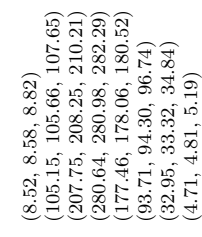 & 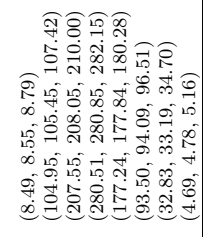 & 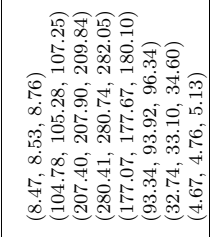 & 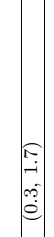 & 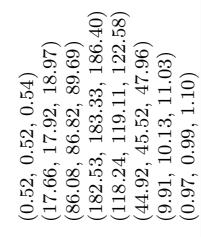 & 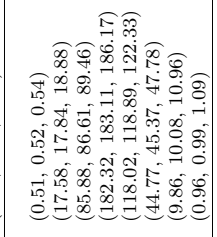 & 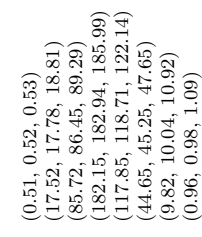 \\
\hline & 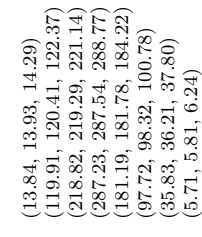 & 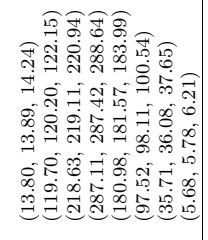 & 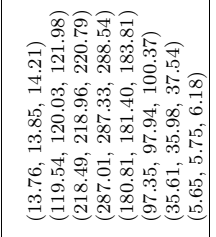 & 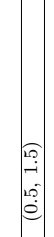 & 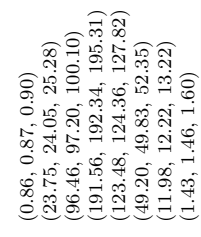 & 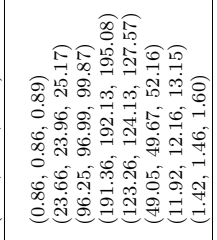 & \\
\hline & 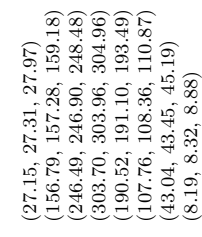 & 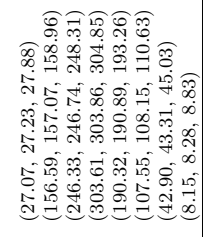 & 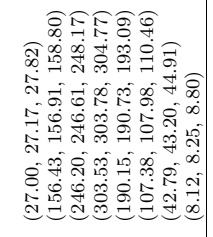 & $\mid \begin{array}{l}\vec{\theta} \\
\vec{x} \mid\end{array}$ & 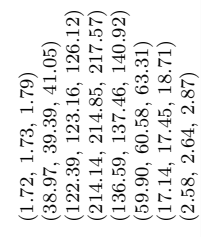 & 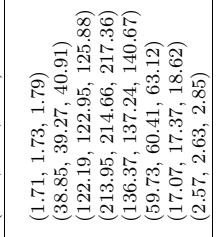 & \\
\hline & & & & & & & \\
\hline
\end{tabular}

Table 11: The out-of-control $A R L_{1}$ of the FSI SH- $\gamma$ chart and the out-of-control $A T S_{1}$ of the VSI SH- $\gamma^{2}$ charts in the presence of measurement errors for different values of $B, \tau, n$, fixed $\eta=0.28, \theta=0.01, m=1, \gamma_{0}=0.05$ (left side), $\gamma_{0}=0.1$ (middle) and $\gamma_{0}=0.2$ (right side); the first row shows the values of $\left(h_{S}, h_{L}\right)$. 


\begin{tabular}{|c|c|c|c|c|c|c|c|}
\hline & 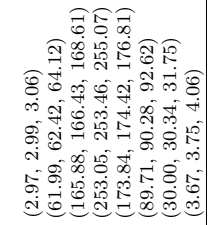 & 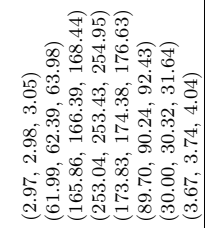 & 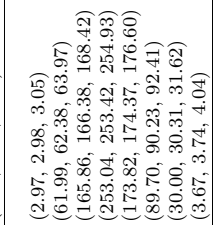 & & 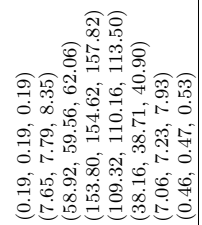 & 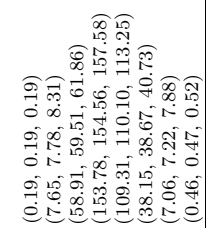 & 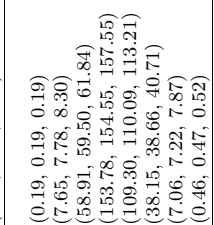 \\
\hline & 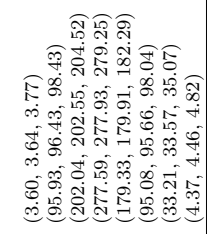 & 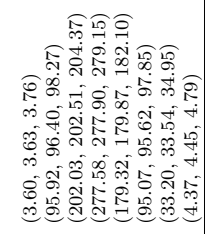 & 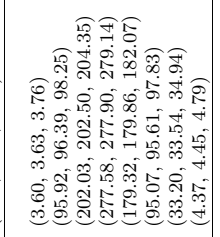 & & 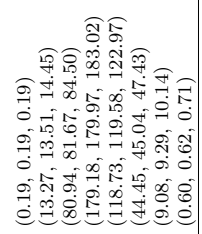 & 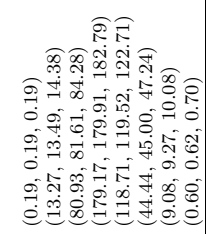 & 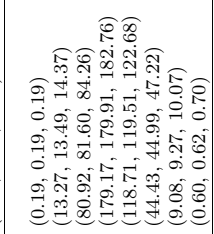 \\
\hline & 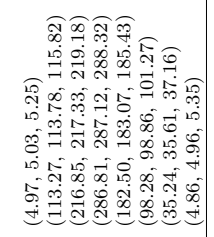 & 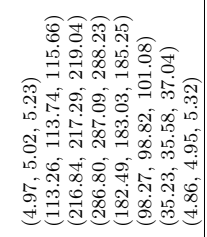 & 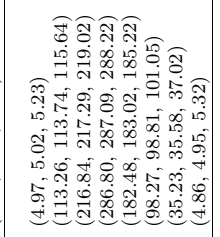 & $\mid$ & 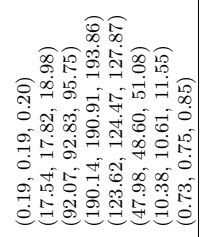 & 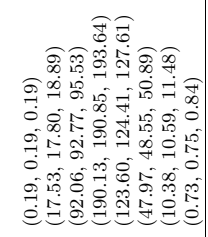 & 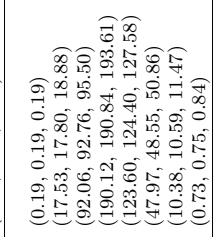 \\
\hline & 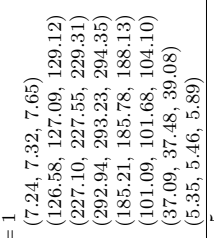 & 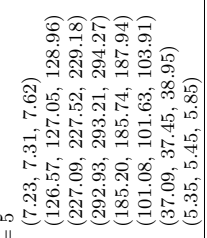 & 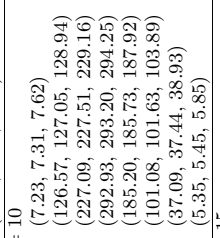 & & 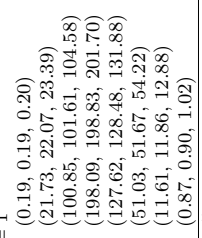 & 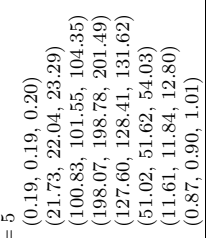 & 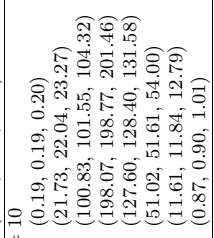 \\
\hline & 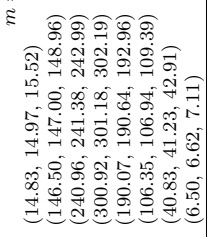 & 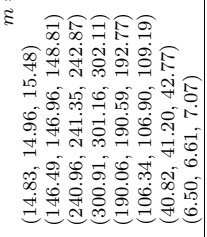 & 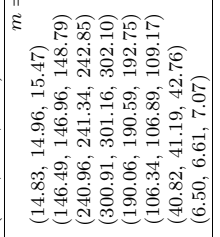 & $\begin{array}{l}\vec{A} \\
\vec{\theta} \\
\vec{e}\end{array}$ & 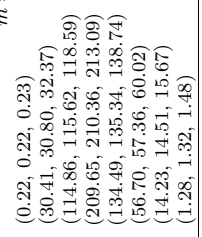 & 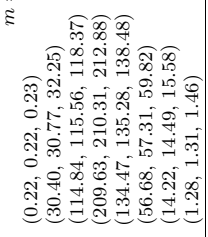 & 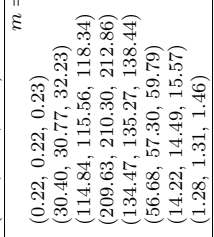 \\
\hline & 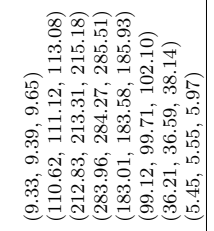 & 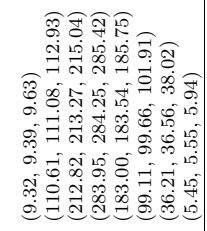 & 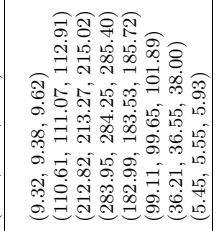 & 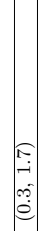 & 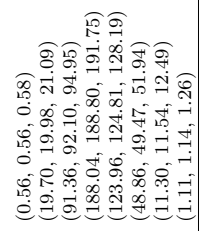 & 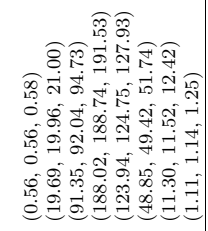 & 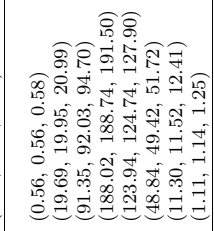 \\
\hline & 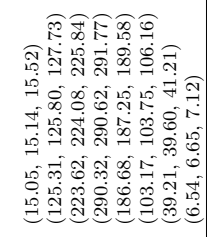 & 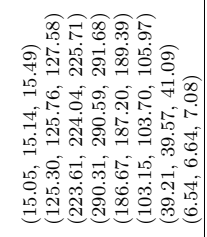 & 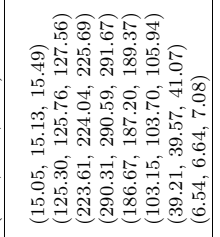 & & 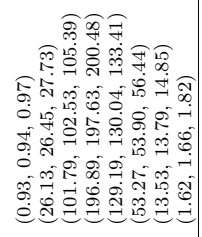 & 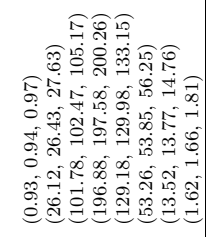 & 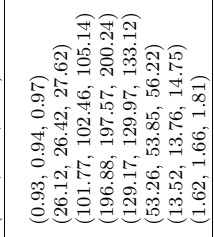 \\
\hline & 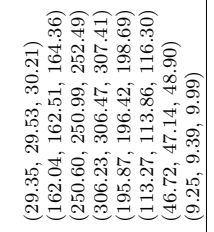 & 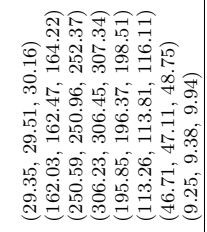 & 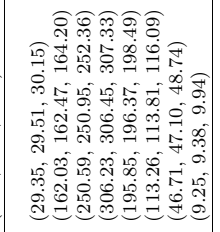 & & 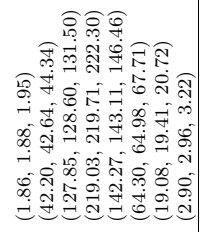 & 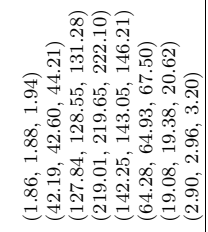 & 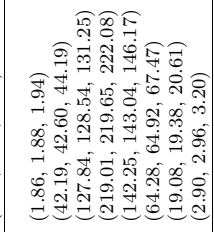 \\
\hline & & & & & & & \\
\hline
\end{tabular}

Table 12: The out-of-control $A R L_{1}$ of the FSI SH- $\gamma$ chart and the out-of-control $A T S_{1}$ of the VSI SH- $\gamma^{2}$ charts in the presence of measurement errors for different values of $m, \tau, n$, fixed $\eta=0.28, \theta=0.05, B=1, \gamma_{0}=0.05$ (left side), $\gamma_{0}=0.1$ (middle) and $\gamma_{0}=0.2$ (right side); the first row shows the values of $\left(h_{S}, h_{L}\right)$. 


\begin{tabular}{|c|c|c|c|c|c|c|c|}
\hline$\Omega$ & $(0.5,1.5)$ & $(0.3,1.7)$ & $(0.1,1.1)$ & $\begin{array}{r}n=5 \\
(0.1,1.3)\end{array}$ & $(0.1,1.5)$ & $(0.1,1.9$ & $(0.1,4.0)$ \\
\hline $\begin{array}{l}\text { (D) } \\
\text { (I) }\end{array}$ & .109.35) & & $\begin{array}{l}(120.54,12 \\
(25,80,25,\end{array}$ & $\begin{array}{c}\eta=0 \\
(105.52,105.84,107.07) \\
(24.00,24.17,24.86)\end{array}$ & & & $(66.51,66$ \\
\hline (D) & $(107.87,108.18,109.41)$ & $(96.98,97.29,98.49)$ & & $\begin{array}{c}(24.00,2.17,24.00) \\
\eta=0.2 \\
(105.53,105.85,107.14)\end{array}$ & & & $(66.52,66.77,67.76)$ \\
\hline (I) & 4,26.19) & $89,24.61)$ & $(25.80$, & $\frac{(24.00,24.18,24.90)}{\eta=0.5}$ & & & $(20.70,20.8)$ \\
\hline $\begin{array}{l}\text { (D) } \\
\text { (I) }\end{array}$ & $\begin{array}{l}(107.89,108.27,109.74) \\
(25.27,25.49,26.40)\end{array}$ & $\begin{array}{l}(97.00,97.37,98.80) \\
(23.73,23.94,24.81)\end{array}$ & $\begin{array}{l}(120.57,120.97,122.56) \\
(25.81,26.04,26.98)\end{array}$ & $\begin{array}{l}(105.55,105.94,107.48) \\
(24.01,24.22,25.11)\end{array}$ & $\begin{array}{l}(96.73,97.11,98.59) \\
(23.14,23.34,24.19)\end{array}$ & $\begin{array}{l}(86.12,86.47,87.87) \\
(22.19,22.39,23.21)\end{array}$ & $\begin{array}{l}(66.53,66.83,68.03) \\
(20.71,20.89,21.66)\end{array}$ \\
\hline $\begin{array}{l}\text { (D) } \\
\text { (I) }\end{array}$ & $\begin{array}{l}(107.97,108.56,110.89) \\
(25.31,25.67,27.19)\end{array}$ & $\begin{array}{l}(97.08,97.66,99.92) \\
(23.77,24.11,25.55) \\
\end{array}$ & $\begin{array}{l}(120.65,121.30,123.80) \\
(25.86,26.22,27.79)\end{array}$ & $\begin{array}{c}\eta=1 \\
(105.63,106.25,108.68) \\
(24.05,24.39,25.86)\end{array}$ & $\begin{array}{r}(96.80,97.40,99.75) \\
(23.18,23.51,24.92)\end{array}$ & $\begin{array}{r}(86.19,86.75,88.96) \\
(22.23,22.55,23.91)\end{array}$ & $\begin{array}{l}(66.59,67.07,68.98) \\
(20.74,21.04,22.31)\end{array}$ \\
\hline & & & & $n=15$ & & & \\
\hline$\Omega$ & $(0.5,1.5)$ & $(0.3,1.7)$ & $(0.1,1.1)$ & $(0.1,1.3)$ & $(0.1,1.5)$ & $(0.1,1.9)$ & $(0.1,4.0)$ \\
\hline (D) & $\begin{array}{l}(40.57,40.82,41.81) \\
(12.65,12.78 .13 .31)\end{array}$ & $\begin{array}{l}(36.09,36.32,37.25) \\
(11.46 .1159 .1208)\end{array}$ & $\begin{array}{l}(44.06,44.34,45.40) \\
(12.98 .13 .12 .13 .67\end{array}$ & $\begin{array}{c}\eta=0 \\
(38.41,38.66,39.64)\end{array}$ & $\begin{array}{l}(35.30,35.53,36.46) \\
(11.01,11.13,11.61)\end{array}$ & $\begin{array}{l}(31.61,31.83,32.70) \\
(10.28,10.39 .10 .85)\end{array}$ & $(24.78,24.97,25.71)$ \\
\hline (D) & $(40.57,40$ & $36.34,37.30)$ & $4.35,45.45)$ & $\begin{array}{c}(11.66,11.79,12.29) \\
\eta=0.2 \\
(38.42,38.68,39.70)\end{array}$ & $0,35.55,36.51)$ & & $(24.78,24.98,25.75)$ \\
\hline (I) & $(12.65,12$ & $(11.47,11.59,12.10)$ & $(12.98,13.12,13.70)$ & $(11.66,11.79,12.32)$ & $(11.01,11.13,11.63)$ & $(10.28,10.40,10.87)$ & $(9.04,9.15,9.57)$ \\
\hline $\begin{array}{l}\text { (D) } \\
\text { (I) }\end{array}$ & $\begin{array}{l}(40.59,40.90,42.13) \\
(12.66,12.82,13.49)\end{array}$ & $\begin{array}{l}(36.11,36.40,37.55) \\
(11.47,11.63,12.24)\end{array}$ & $\begin{array}{l}(44.09,44.43,45.74) \\
(12.99,13.16,13.86)\end{array}$ & $\begin{array}{c}\eta=0.5 \\
(38.44,38.75,39.96) \\
(11.67,11.83,12.46)\end{array}$ & $\begin{array}{l}(35.32,35.61,36.77) \\
(11.02,11.17,11.77)\end{array}$ & $\begin{array}{l}(31.63,31.90,32.98) \\
(10.29,10.43,11.00)\end{array}$ & $\begin{array}{l}(24.80,25.03,25.95) \\
(9.05,9.18,9.69)\end{array}$ \\
\hline (D) & $\begin{array}{l}(40.65,41.15,43.07) \\
(12.69 .12 .95,14.03)\end{array}$ & $\begin{array}{l}(36.17,36.64,38.44) \\
(11.50 .11 .75,12.75)\end{array}$ & $\begin{array}{l}(44.16,44.69,46.76) \\
(13.03 .13 .30 .14 .42)\end{array}$ & $\begin{array}{c}\eta=1 \\
(38.50,38.99,40.90) \\
(11.70,11.95,12.98)\end{array}$ & $\begin{array}{l}(35.38,35.85,37.66) \\
(11.05,11.29,12.26\end{array}$ & $\begin{array}{l}(31.68,32.12,33.81) \\
(10.32,10.54,11.46\end{array}$ & $\begin{array}{l}(24.84,25.22,26.67) \\
(9.08,928,10.10)\end{array}$ \\
\hline
\end{tabular}

Table 13: The effect of $\eta$ on the overall performance of the VSI SH- $\gamma^{2}$ control charts in the presence of measurement errors for $B=1, m=1, \theta=0.05, n=\{5,15\}, \gamma_{0}=0.05$ (left side), $\gamma_{0}=0.1$ (middle) and $\gamma_{0}=0.2$ (right side).

\begin{tabular}{|c|c|c|c|c|c|c|c|}
\hline$\Omega$ & & & & $\begin{array}{r}n=5 \\
\end{array}$ & & & \\
\hline$\Omega 2$ & $(0.5,1.5)$ & $(0.3,1.7)$ & $\begin{array}{l}(0.1,1.1) \\
\end{array}$ & $\frac{(0.1,1.3)}{\theta=0}$ & $(0.1,1.5)$ & $(0.1,1.9)$ & $(0.1,4.0)$ \\
\hline (D) & $21,105.58)$ & $(93.12,93$. & $(116.13,116.51,118.00)$ & $(101.33,101.69,103.13)$ & $(92.71,93.06,94.43)$ & $32.71,84.00)$ & $9,64.79)$ \\
\hline & $.68,24.50)$ & $(22.03,22.22,22.99)$ & $(23.98,24.18,25.02)$ & $(22.28,22.47,23.26)$ & $(21.46,21.64,22.40)$ & $(20.58,20.75,21.48)$ & $(19.18,19.35,20.03)$ \\
\hline & $(106.28,106.62,107.93)$ & $(95.45,95.78,97.05)$ & $(118.80,119.16,120.58)$ & $\begin{array}{c}\theta=0.03 \\
(103.86,104.21,105.58)\end{array}$ & & & $(65.28,65.55,66.61)$ \\
\hline (I) & $(24.55,24.74,25.53)$ & $(23.04,23$. & $(25.07,2$ & $(23.31,23.50,24.26)$ & $(22.4$ & $(21.54$, & $(20.09,20.25,20.92)$ \\
\hline & & & & $\begin{aligned} \theta & =0.05\end{aligned}$ & & & \\
\hline & $\begin{array}{l}(107.87,10 \\
(25,26,25\end{array}$ & ,98.54) & $120.90,122.28)$ & (105.53,105.87,1 & & & \\
\hline & & & & $\frac{(24.00,24.18,24.9}{n=15}$ & $(23.13,23.30$ & $(22.19,22.35,23.06)$ & $(20.70,20.86,21.51)$ \\
\hline$\Omega$ & $(0.5,1.5)$ & $(0.3,1.7)$ & $(0.1,1.1)$ & $(0.1,1.3)$ & $(0.1,1.5)$ & $(0.1,1.9)$ & $(0.1,4.0)$ \\
\hline & & & & $\begin{aligned} \theta & =0\end{aligned}$ & & & \\
\hline (D) & $(38.37,38.66,39.78)$ & $(34.04,34.31,35.36)$ & $(41.69,42.00,43.21)$ & $(36.24,36.53,37.64)$ & $(33.25,33.52,34.57)$ & $(29.71,29.96,30.94)$ & $(23.18,23.39,24.23)$ \\
\hline (I) & $(11.68,11.83,12.42)$ & $(10.56,10.70,11.25)$ & $(11.97,12.12,12.74)$ & $(10.73,10.87,11.44)$ & $(10.12,10.26,10.79)$ & $(9.44,9.57,10.07)$ & $(8.29,8.40,8.85)$ \\
\hline (D) & $(39.70,39.97,41.06)$ & $(35.27,35.53,36.55)$ & $(43.12,43.42,44.59)$ & $\begin{array}{c}\theta=0.03 \\
(37.55,37.83,38.90)\end{array}$ & $(34.48,34.74,35.77)$ & $(30.85,31.10,32.05)$ & $(24.14,24.35,25.16)$ \\
\hline (I) & $(12.26,12.40,12.98)$ & $(11.10,11.24,11.77)$ & $(12.58,12.73,13.33)$ & $(11.29,11.4$ & $(10.65,10.78,11.31)$ & $(9.95,10.07,10.56)$ & $(8.74,8.85,9.29)$ \\
\hline (D) & & & & $\begin{array}{c}\theta=0.05 \\
(38.42,38.69,39.74)\end{array}$ & & & $(24.79,24.99,25.78)$ \\
\hline & $(12.65,12.79,13.37)$ & $(11.47,11.60,12.13)$ & $(12.98,13.13,13.73)$ & $(11.66,11.80,12.34)$ & $(11.01,11.14,11.66)$ & $(10.28,10.41,10.89)$ & $(9.04,9.15,9.59)$ \\
\hline
\end{tabular}

Table 14: The effect of $\theta$ on the overall performance of the VSI SH- $\gamma^{2}$ control charts in the presence of measurement errors for $B=1, m=1, \eta=0.28, n=\{5,15\}, \gamma_{0}=0.05$ (left side), $\gamma_{0}=0.1$ (middle) and $\gamma_{0}=0.2$ (right side). 


\begin{tabular}{|c|c|c|c|c|c|c|c|}
\hline$\Omega$ & $(0.5,1.5)$ & $(0.3,1.7)$ & $(0.1,1.1)$ & $\begin{array}{c}n=5 \\
(0.1,1.3)\end{array}$ & $(0.1,1.5)$ & $(0.1,1.9)$ & $(0.1,4.0)$ \\
\hline & & & & $\begin{array}{c}B=1 \\
(102.18,102.54,103.95\end{array}$ & & & \\
\hline (I) & $(23.84,24.03,24.84)$ & $\begin{array}{l}(22.37,22.55,23.32) \\
(22.5,3\end{array}$ & $(24.34,24.54,25.37)$ & $\begin{array}{l}(102.18,102.25,4103 . \\
(22.63,22.81,23.59)\end{array}$ & $\begin{array}{r}(93.52,93.86,95.22) \\
(21.79,21.97,22.73)\end{array}$ & $\begin{array}{r}(83.13,83.45,84.73) \\
(20.90,21.07,21.79)\end{array}$ & $\begin{array}{r}(64.04,64.31,65.40) \\
(19.48,19.65,20.32)\end{array}$ \\
\hline & & & & $B=3$ & & & \\
\hline (D) & $\begin{array}{l}(104.12,104.45,105.73) \\
(23.60,23.78,24.54)\end{array}$ & $\begin{array}{l}(93.37,93.69,94.93) \\
(22.14,22.31 .23 .03\end{array}$ & $\begin{array}{l}(116.42,116.78,118.17) \\
(24.10,24.28,25.06)\end{array}$ & $\begin{array}{l}(101.61,101.94,103.28) \\
(22,39,22.57,23,30)\end{array}$ & $\begin{array}{l}(92.97,93.29,94.58) \\
(21.57,21.74 .22 .44)\end{array}$ & $\begin{array}{l}(82.62,82.93,84.13) \\
(2068.20 .84 .1522\end{array}$ & $\begin{array}{r}(63.61,63.87,64.90) \\
(19.28,19.43 .20 .07)\end{array}$ \\
\hline (D) & & & $(116.30,116.66,118.04)$ & $\begin{array}{l}\frac{B}{B=5} \\
(101.49,101.83,103.16)\end{array}$ & $(21.01,21.1,125.197)$ & $(20.00,20.01,21.02)$ & \\
\hline (I) & $(23.55,23.74,24.49$ & $(22.10,22.27,22.98)$ & $(24.05,24.23,25.01)$ & $(22.35,22.52,23.25)$ & $(21.52,21.69,22.39)$ & $(20.64,20.80,21.47)$ & $(19.24,19.39,20.02)$ \\
\hline & & & & $n=15$ & & & \\
\hline$\Omega$ & $(0.5,1.5)$ & $(0.3,1.7)$ & $(0.1,1.1)$ & $(0.1,1.3)$ & $(0.1,1.5)$ & $(0.1,1.9)$ & $(0.1,4.0)$ \\
\hline & & & & $\begin{array}{c}B=1 \\
(36.68,36.96,38.06)\end{array}$ & & $(30.09,30.34,31.31)$ & $(23.50,23.71,24.54)$ \\
\hline (I) & $(11.87,12.02,12.61)$ & $(10.74,10.88,11.42)$ & $(12.17,12.32,12.94)$ & $\begin{array}{r}(10.92,11.06,11.62) \\
(1)\end{array}$ & $\begin{array}{l}(10.30,10.43,10.96) \\
(\end{array}$ & 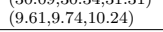 & $\begin{array}{l}(8.44,8.55,9.00) \\
(2)\end{array}$ \\
\hline (D) & & & & $\begin{array}{c}B=3 \\
(36.38,36.65,37.69)\end{array}$ & & & 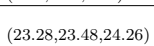 \\
\hline (I) & $(11.74,11.88,12$. & $(10.62,10.75,11.26)$ & $(12.03,12.18,12.75)$ & $(10.79,10.92,11.45)$ & $(10.18,10.30,10.80)$ & $\begin{array}{l}(9.50,9.61,10.08) \\
\text { ( })\end{array}$ & $(8.34,8.44,8.86)$ \\
\hline (D) & & & & $\begin{array}{c}B=5 \\
(36.33,36.59,37.63)\end{array}$ & & & $(23.24,23.44,24.22)$ \\
\hline (I) & $(11.72,11.85,12.40)$ & $(10.60,10.72,11.23)$ & $(12.01,12.15,12.72)$ & $(10.77,10.90,11.42)$ & $(10.16,10.28,10.77)$ & $(9.48,9.59,10.06)$ & $(8.32,8.42,8.84)$ \\
\hline
\end{tabular}

Table 15: The effect of $B$ on the overall performance of the VSI SH- $\gamma^{2}$ control charts in the presence of measurement errors for $\theta=0.01, m=1, \eta=0.28, n=\{5,15\}, \gamma_{0}=0.05$ (left side), $\gamma_{0}=0.1$ (middle) and $\gamma_{0}=0.2$ (right side).

\begin{tabular}{|c|c|c|c|c|c|c|c|}
\hline 8 & $(0,5,1,5)$ & $(0.3,1.7$ & $(0,1,1,1)$ & $\begin{array}{r}n=5 \\
(0.1 .1 .3)\end{array}$ & $(0,15)$ & $(0,19)$ & $(0,40)$ \\
\hline (D) & $\begin{array}{l}(107.87,108.20,109.47) \\
(25.26,25.45,26.23)\end{array}$ & $\begin{array}{l}(96.99,97.30,98.54) \\
(23.72,23.90,24.64)\end{array}$ & $\begin{array}{l}(120.55,120.90,122.28) \\
(25.80,2600,26,80)\end{array}$ & $\begin{array}{c}m=1 \\
(105.53,105.87,107.20) \\
(24.00,24.18,24,94)\end{array}$ & $\begin{array}{l}(96.71,97.04,98.32) \\
(23.13 .23 .30 .24 .03)\end{array}$ & $\begin{array}{l}(86.10,86.41,87.62) \\
(22.1922 .35 .2306)\end{array}$ & $(66.52,66.78,67.81)$ \\
\hline (D) & $\begin{array}{l}(107.87,108.17,109.37) \\
(25,26,25.33,26.17)\end{array}$ & $(96.98,97.28,98.45)$ & $(120.54,120.87,122.17)$ & $\begin{array}{c}m=5 \\
(105.52,105.84,107.10)\end{array}$ & $(96.70,97.01,98.22)$ & $(86.10,86.38,87.52)$ & $(66.51,66.76,67.73)$ \\
\hline $\begin{array}{l}\text { (D) } \\
\text { (I) }\end{array}$ & $\begin{array}{l}(107.87,108.17,109.36) \\
(25.26,25.43,26.16)\end{array}$ & $\begin{array}{l}(96.98,97.28,98.44) \\
(23.72,23.89,24.58)\end{array}$ & $\begin{array}{l}(120.54,120.87,122.16) \\
(25.80,25.98,26.73)\end{array}$ & $\begin{array}{c}(24.00,24.17,24.88) \\
m=10 \\
(105.52,105.84,107.09) \\
(24.00,24.17,24.87)\end{array}$ & $\begin{array}{l}(96.70,97.01,98.21) \\
(23.12,23.29,23.97)\end{array}$ & $\begin{array}{l}(86.09,86.38,87.51) \\
(22.18,22.34,22.99)\end{array}$ & $\begin{array}{l}(66.51,66.76,67.72) \\
(20.70,20.84,21.45)\end{array}$ \\
\hline & & & & $n=15$ & & & \\
\hline$\Omega$ & $(0.5,1.5)$ & $(0.3,1.7)$ & $(0.1,1.1)$ & $(0.1,1.3)$ & $(0.1,1.5)$ & $(0.1,1.9)$ & $(0.1,4.0)$ \\
\hline $\begin{array}{l}\text { (D) } \\
\text { (I) }\end{array}$ & $\begin{array}{l}(40.57,40.85,41.91) \\
(12.65,12.79,13.37)\end{array}$ & $\begin{array}{l}(36.09,36.35,37.35) \\
(11.47,11.60,12.13)\end{array}$ & $\begin{array}{l}(44.07,44.36,45.51) \\
(12.98 .13 .13,13.73)\end{array}$ & $\begin{array}{c}m=1 \\
(38.42,38.69,39.74) \\
(11.66,11.80,12.34)\end{array}$ & $\begin{array}{l}(35.30,35.56,36.56) \\
(11.01,11.14,11.66)\end{array}$ & $\begin{array}{l}(31.61,31.85,32.79) \\
(10.28,10.41,10.89)\end{array}$ & $\begin{array}{l}(24.79,24.99,25.78) \\
(9.04,9.15,9.59)\end{array}$ \\
\hline (D) & $\begin{array}{l}(40.57,40.83,41.83) \\
(12.65 .12 .78 .13 .32\end{array}$ & $\begin{array}{l}(36.09,36.33,37.27) \\
(11.46 .11 .59 .1209)\end{array}$ & $\begin{array}{l}(44.07,44.34,45.42) \\
(12.98 .1312 .1368)\end{array}$ & $\begin{array}{c}m=5 \\
(38.42,38.67,39.66) \\
(11.66 .1179 .12 .30)\end{array}$ & $\begin{array}{l}(35.30,35.54,36.48) \\
(1101.1131162\end{array}$ & $\begin{array}{l}(31.61,31.83,32.71) \\
(10.28,10.40 .10,86)\end{array}$ & $(24.78,24.97,25.72)$ \\
\hline $\begin{array}{l}\text { (D) } \\
\text { (I) }\end{array}$ & $\begin{array}{l}(40.57,40.82,41.82) \\
(12.65,12.78,13.32)\end{array}$ & $\begin{array}{l}(36.09,36.33,37.26) \\
(11.46,11.59,12.08)\end{array}$ & $\begin{array}{l}(44.07,44.34,45.41) \\
(12.98,13.12,13.68)\end{array}$ & $\begin{array}{c}m=10 \\
(38.41,38.67,39.65) \\
(11.66,11.79,12.30)\end{array}$ & $\begin{array}{l}(35.30,35.54,36.47) \\
(11.01,11.13,11.61)\end{array}$ & $\begin{array}{l}(31.61,31.83,32.70) \\
(10.28,10.39,10.85)\end{array}$ & $\begin{array}{l}(24.78,24.97,25.72) \\
(9.04,9.14,9.55)\end{array}$ \\
\hline
\end{tabular}

Table 16: The effect of $m$ on the overall performance of the VSI SH- $\gamma^{2}$ control charts in the presence of measurement errors for $B=1, \theta=0.05, \eta=0.28, n=\{5,15\}, \gamma_{0}=0.05$ (left side), $\gamma_{0}=0.1$ (middle) and $\gamma_{0}=0.2$ (right side). 